\title{
BUILDING. SHARING. CONNECTING.
}

Annual Report and

Annual Knowledge Transfer Survey 2014 


\section{In 2014}

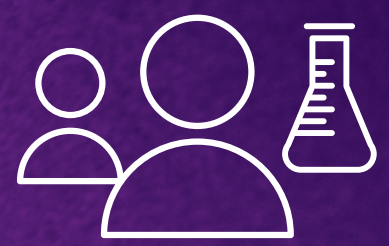

\section{PRODUCTS ON} THE MARKET

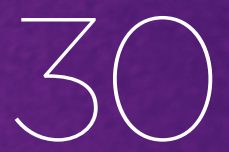

new products were launched on the market in 2014 as the result of a licence from an RPO This is consistent with the previous year's figure of 31 new products available for consumer or commercial use.

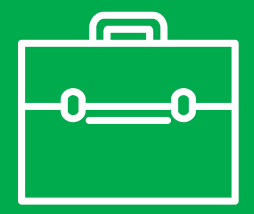

BUSINESSES ENGAGED IN RESEARCH AGREEMENTS

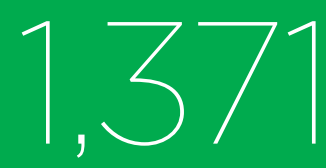

the number of different companies RPOs worked with in collaborative or contract research programmes, which is a $46 \%$ increase over the previous year.

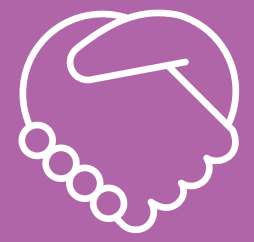

RESEARCH AGREEMENTS

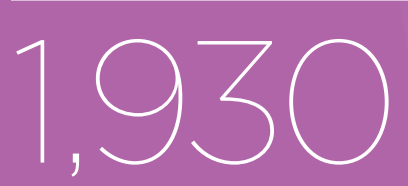

new collaborative and contract agreements signed in 2014.

\section{RESEARCH AND} CONSULTANCY AGREEMENTS

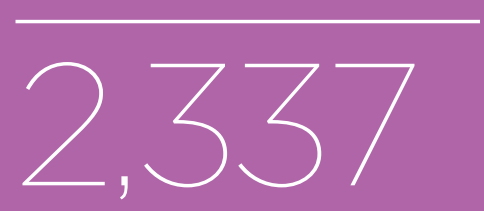

new agreements (collaborative and contract research and consultancy) were signed with companies, representing a $46 \%$ increase from 2013.

\section{LICENCES/OPTIONS/ ASSIGNMENTS (LOAs)}

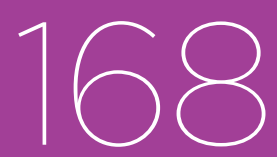

there was a continued increase in the number of LOAs signed to 168 , up $21 \%$ from the previous year.

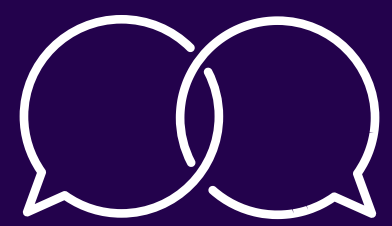

COLLABORATION WITH IRISH SMES

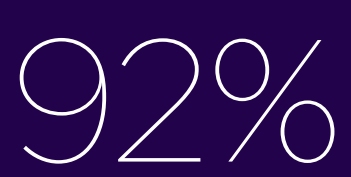

of research agreements (contract and collaborative research) with the SME sector were with Irish SMES.

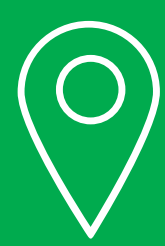

\section{COMPANY} LOCATION

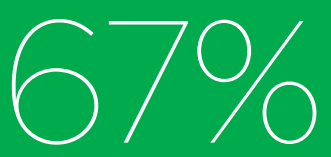

of companies working with RPOs on research agreements (contract and collaborative research) were based in Ireland. 


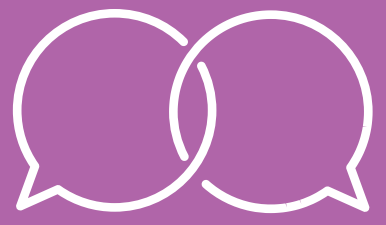

COLLABORATION WITH IRISH MNCS

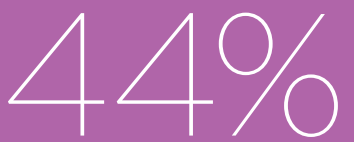

of research agreements (contract and collaborative research) with the MNC sector were with Irish-based MNCs.

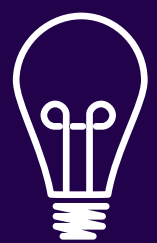

\section{INVENTION} DISCLOSURES

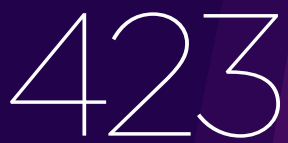

new invention disclosures, a decrease of 9\% from 2013 .

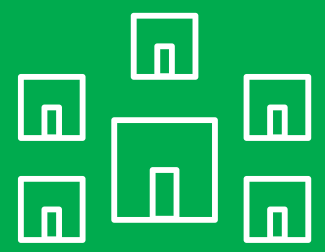

\section{SPIN-OUTS}

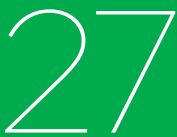

new spin-out companies were formed, a drop of $27 \%$ on the previous year.

ACTIVE SPIN-OUTS

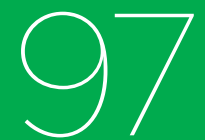

active spin-outs, thriving at least three years postincorporation at the end of 2014, an increase of $21 \%$ on the number at the same time the previous year.

CONSULTANCY AGREEMENTS

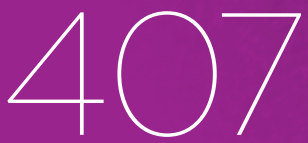

the number recorded has dropped by $23 \%$ on the previous year to 407.

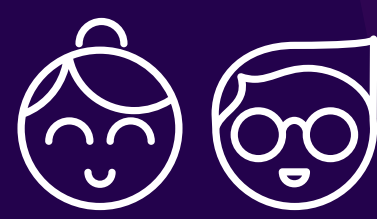

PRIORITY

PATENT

APPLICATIONS

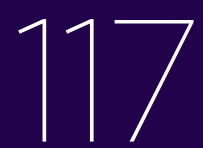

patent applications were filed, which is consistent with the previous year.

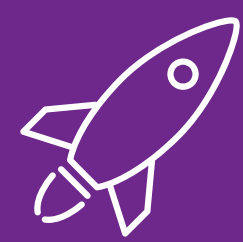

INCUBATOR FACILITIES

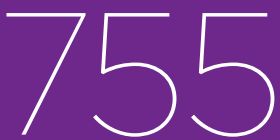

companies incubated in HEl incubator facilities. 


\section{Contents}

\begin{tabular}{|c|c|c|}
\hline & & Annual Report \\
\hline 05 & I & Foreword \\
\hline 06 & 1 & Introduction \\
\hline 08 & 1 & 2014 Highlights \\
\hline 18 & l & The Team \\
\hline
\end{tabular}

\section{Annual Knowledge Transfer Survey 2014}

20 1. Executive summary

22 2. Research funding in Ireland

23 | 3. Business access to research and expertise within Ireland's RPOs

25 | $3.1 \quad$ Working with Irish companies

\begin{tabular}{l|ll}
25 & 3.2 & Research with business
\end{tabular}

27 | 3.3 Consultancy to business

28 4. Research and consultancy with non-commercial organisations

29 | 5. Revenue from research agreements and consultancy

29 | $5.1 \quad$ Total revenue from collaborative research and contract research

29 | 5.2 Revenue from consultancy

30 | 6. Invention disclosures

$31 \quad$ 7. Patent activity

\begin{tabular}{l|ll}
32 & 7.1 & RPO patent portfolio
\end{tabular}

32 | 7.2 Initial patent filings

33 | $7.3 \quad$ PCT applications

$34 \quad 7.4 \quad$ Patents granted

34 | 7.5 Reimbursement of patent costs

35 | $8 . \quad$ Licensing of rights

35 | 8.1 Licences, options and assignments (LOAs)

38 | 8.2 Types of IP licensed

40 | 8.3 Licensees

41 | 8.4 Material transfer agreements (MTAs)

41 | 8.5 Products on the market

42 9. Company creation

42 | $9.1 \quad$ New companies

44 | 9.2 Active spin-out companies

45 | 9.3 Spin-in companies

45 | 9.4 Company incubation

47 | 10. Revenue generation from licensing and spin-outs

48 | $10.1 \quad$ Licence revenue

48 | 10.2 Revenue from equity sale

49 | 11. Use of facilities and equipment

50 | 12. Summary of commercialisation revenue

51 | $13 . \quad$ Knowledge transfer infrastructure

\section{Appendices}

52 | Appendix 1: Summary data by RPO

59 | Appendix 2: List of Research Performing Organisations (RPOs)

60 | Appendix 3: Glossary 


\section{Foreword}

Knowledge Transfer Ireland (KTI) is an initiative supported by Enterprise Ireland in partnership with the Irish Universities Association. We established KTI in late 2013 and I am pleased to introduce this Annual Report 2014 which charts its significant progress within a relatively short time frame.

Innovation in Ireland is thriving, and the ability of companies to connect with and draw from the Irish research base is an important component in driving competitiveness, whether this be through collaboration, acquiring novel intellectual property or in the creation of new ventures. For these activities to flourish, Ireland needs a dynamic system to transfer knowledge and technology into industry effectively and efficiently. This is a critical element in driving a return on the State's investment in Higher Education R\&D, which stood at $€ 649$ million in 2013, and in creating innovative businesses and jobs in Ireland.

Through the Technology Transfer Strengthening Initiative (TTSI) programme, Enterprise Ireland has invested in developing the capability and capacity to support knowledge transfer and commercialisation in our research performing organisations (RPOs). We see this infrastructure as a core component of delivery to the innovation agenda. In 2014, our investment through the TTSI 2 programme saw a $21 \%$ increase in the number of licence agreements and the number of three-year active spin-out companies has risen by a similar percentage. Supported by KTI, Ireland now has a unique window for industry, enabling swift access to technologies and expertise within the Irish research base and providing tools to support engagement.

It is important that we have a national perspective on the performance and management of the Irish knowledge transfer system, a role that KTI has taken on for the State. As the Annual Knowledge Transfer Survey

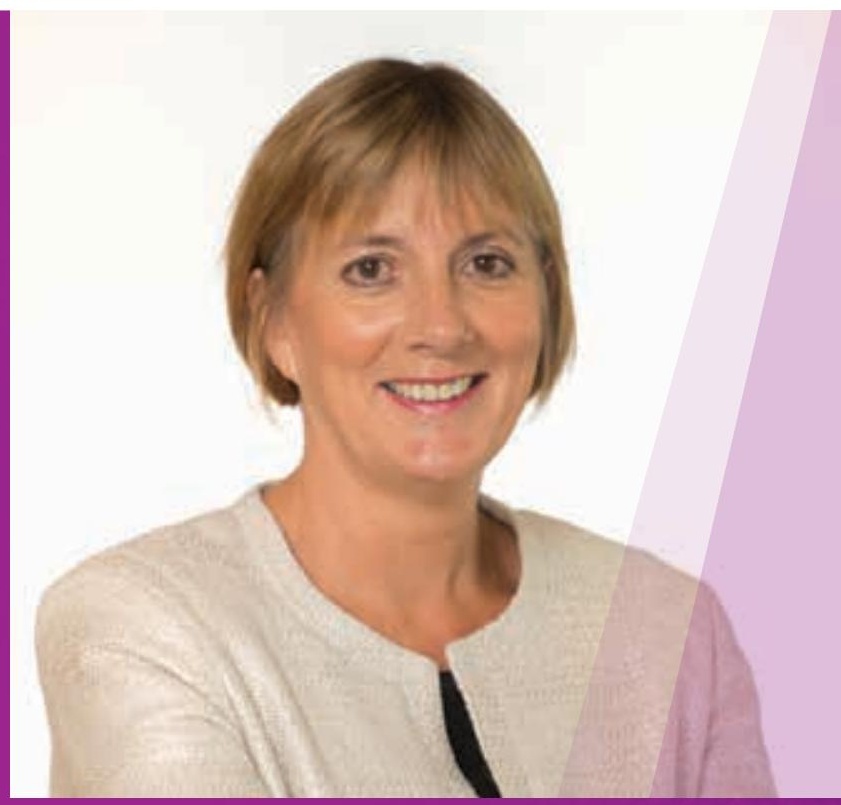

establishes, we have time series data that will enable us to map and compare our progress against others as we begin to probe the impact of our investments in academic R\&D - the greatest impact of which is the development of a workforce of skilled graduates who will go on to be Ireland's innovators of the future.

There are many strong success stories of innovation from the Irish research base. Research and consultancy agreements signed between industry and the research base have risen to almost 2,000 in 2014; just under $70 \%$ of these are with Irish companies.

This Annual Report highlights some of the successes that gained prominence in 2014. Frequently, the underpinning R\&D has received funding from a variety of sources including infrastructure funding through the HEA, peer reviewed research funding from Science Foundation Ireland, and innovation funding from Enterprise Ireland. At the heart of success, though, are people. The researchers, funders, industry partners, investors, commercial champions and the technology transfer professionals all work with a shared ambition to maximise the potential of research and to make great things happen for Ireland.

\section{Julie Sinnamon}

CEO, Enterprise Ireland 
Since our launch, we have commissioned a series of reviews of aspects of the KT system in Ireland. In May KTI published a review of the TTSI1 programme, which demonstrated the impact of State investment to grow commercialisation support in Irish universities. Following the publication of the AKTS 2013, $\mathrm{KTI}$ undertook a study probing further into the products brought to market in 2013 and exploring the sustainable companies created from the RPO base. Those results can be found in the AKTS 2014, later in this Annual Report.

$\mathrm{KTI}$ has continued to work with the main Irish research and innovation funding agencies to assist in streamlining IP management and commercial contracts. The technology transfer offices have been proactive in this regard, giving up time to share their experience and contribute to specific task forces with $\mathrm{KTI}$ and with the agencies.

In the second half of 2014, KTI initiated a review of the national IP Protocol, consulting over 100 companies and stakeholders. The resultant recommendation for changes to aspects of the Protocol will be implemented in 2015, supported by further Model Agreements and Practical Guides that serve as a framework for business-RPO contracting.

The Technology Transfer Strengthening Initiative (TTSI2) is an Enterprise Ireland funding programme that provides commercialisation support to RPOs. As it is responsible for managing this programme, $\mathrm{KTI}$ undertook a midterm review of the process towards the end of 2014. I am pleased to report that the international review panel was enthusiastic about how much the programme had been able to achieve for Ireland in a relatively short time frame. This is underscored by the strong results revealed in the AKTS 2014.
Our challenge going forward is to manage TTSI2 to its conclusion in 2016 and to prepare for the next phase. The successor programme will need to be flexed to enable an expanded and more nuanced remit within RPOs, enhancing the recent evolution from traditional IP-centric technology transfer support to a more holistic knowledge transfer support system that benefits industry more fully.

$\mathrm{KTI}$ has established the $\mathrm{KT}$ Stakeholder Forum as a community of innovation leaders within government agencies and the RPOs with whom we can work to drive forward strategy and implementation of best, and new, practice.

Committed to ensuring translation of knowledge and its impact for the economy and society, the KTSF is a lively and informative group.

$\mathrm{KTI}$ is fortunate to have an Industry Advisory Board composed of senior figures from the business and investment sectors. I am grateful to our IAB members who so generously give up their time not just to share their experience with $\mathrm{KTI}$, but also to undertake additional activities for us. We look forward to working with all our stakeholders in the year ahead as we build on the foundations laid in our first year of operation.

\section{Dr. Alison Campbell OBE RTTP} Director, KTI 


\section{Highlights of 2014}

At the start of the year, $\mathrm{KTI}$ was in establishment phase, bringing together its Industry Advisory Board, forming the KT Stakeholder Forum and developing resources for its launch in May. Richard Bruton T.D., Minister for Jobs, Enterprise and Innovation formally launched KTI explaining that the formation of KTI advances the Government's plan to strengthen and standardise the Irish knowledge transfer system with the key objective of maximising the economic and societal benefits from State-funded research, in particular the creation of sustainable jobs.

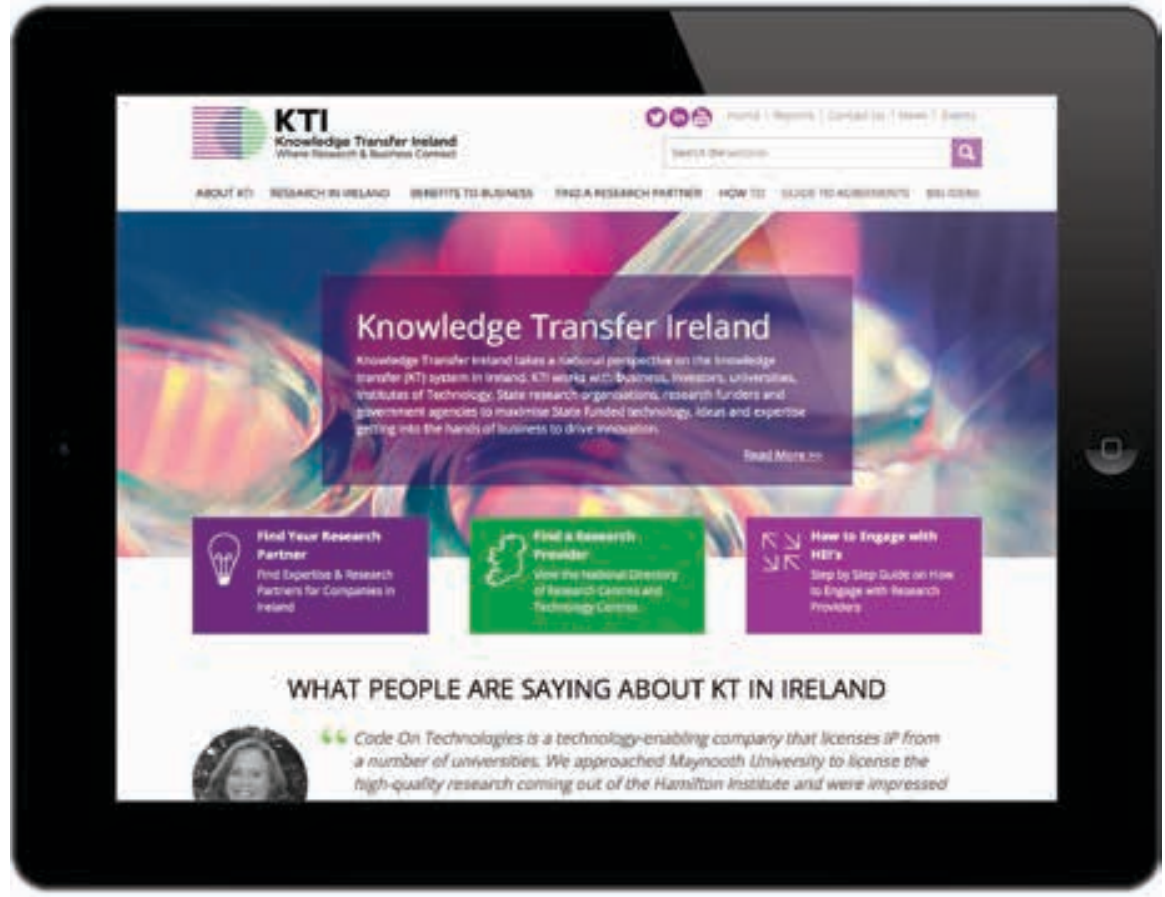

\section{KTI web portal expands}

The KTI web portal went live in May and during the year has become a more powerful and much needed resource for industry. New features since the portal was launched include:

- New licensing opportunities that provide industry with even more potential for innovation

- The national Directory of Research Centres and Technology Centres which showcases the excellent scientific research at State-funded centres of scale, delivering impactful technologies for industry in 14 areas of national priority

- Reports on knowledge transfer best practice

- New case studies that illustrate the positive benefits for society and the economy resulting from industry-research collaborations

- An expanded news and events section that is the go-to source for all matters relating to knowledge transfer

This is in addition to the core functionality of the web portal that includes:

- Databases that enable companies to search for:

- New ideas and technologies available for licensing
- Research specialists and research facilities to optimise R\&D opportunities and overcome challenges

- A step-by-step guide, which explains what can be expected throughout the interaction process, supported by checklists and questionnaires to help prepare for meetings with the TTOs and researchers

- A suite of model agreements, which includes:

- Confidential Disclosure Agreement

- Model Licence Agreement (exclusive and non-exclusive)

- Model Option Agreement

- Model Evaluation Agreement

- Model Material Transfer Agreement

- A series of KTI Practical Guides to contracts designed to make the process of contracting between business and the research base simple and understandable

- Direct links to TTOs and individuals within the research sector

The KTI web portal was selected as a finalist in the Web Awards 2014 in the Local Government and Government category. 


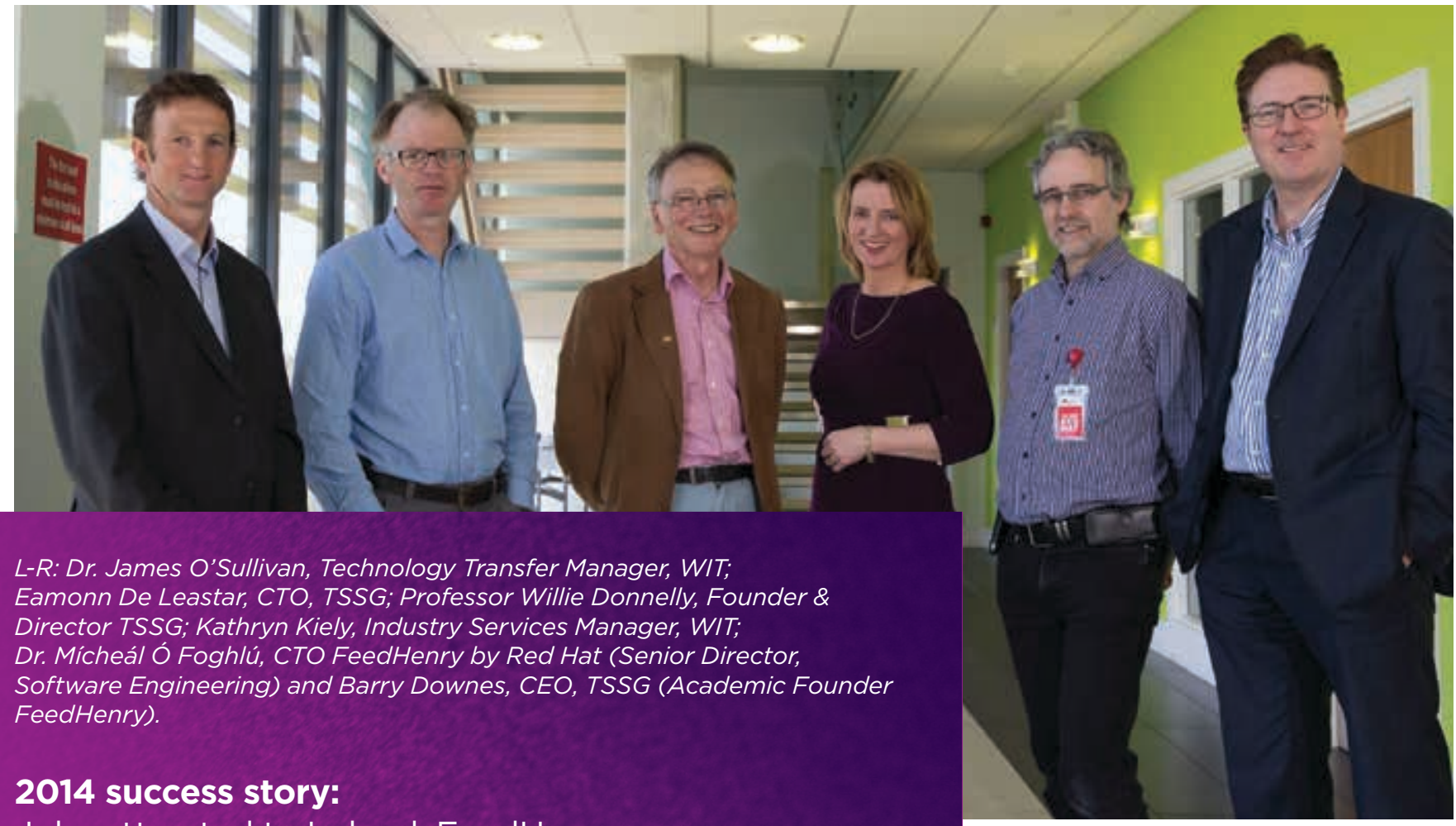
Jobs attracted to Ireland: FeedHenry

FeedHenry is noted for securing the second-highest valuation to date for a business developed from a spinout from an Irish higher education institution. In 2014 it was acquired by Red Hat Inc for US\$82 million.

FeedHenry was born of the commercialisation of a research programme led by Barry Downes into next-generation service delivery platforms and services. Having secured some commercial contracts, Downes focused the FeedHenry offering in 2010, creating an end-to-end cloud service provider for mobile applications.

Since it was spun out of the Telecommunications Software and Systems Group (TSSG) at Waterford Institute of Technology (WIT), FeedHenry has created 52 jobs in Waterford, 10 in Dublin and about 20 more across its offices in Boston, London and San Francisco.

Following the acquisition, Red Hat is the first global software company to have a presence in the south-east of Ireland and is already an important anchor for a local cluster of high-tech companies.

The FeedHenry project has been an innovation catalyst. Many of the TSSG staff who worked on it have since started up their own companies, such as nearForm and StitcherAds (formerly Betapond). The development of the technology underpinning FeedHenry has had significant impact on the region and, in particular, has been instrumental in establishing

Waterford as a globally recognised competence centre for node development and consultancy.

The vision to create a spin-out company from research in TSSG and the persistence to develop it relied on champions within the research team, WIT management, the TTO and Enterprise Ireland.

\section{Added value from the Institute} of Technology: intellectual property, licence, spin-out company creation, company incubation, research collaboration 


\section{Working with stakeholders}

\section{Funder engagement}

KTI has been working with Ireland's research funders in the drive for further simplicity in contractual arrangements that underpin national collaborative R\&D funding programmes. For example, KTI worked with Science Foundation Ireland (SFI) and a task force of legal and technology transfer specialists as they reviewed experience gained to date in negotiating these particular bilateral collaboration agreements that underpin the first round of the SFI research centres programme. The Irish Research Council (IRC), with advice from $\mathrm{KTI}$, updated the terms and conditions of its Employment Based Postgraduate Programme to better reflect the operational details of the scheme. KTI has also, at Enterprise Ireland's request, supported its programme manager and a working group including technology transfer directors to develop a Heads of Agreement template for Enterprise Ireland's Innovation Partnership Programme.

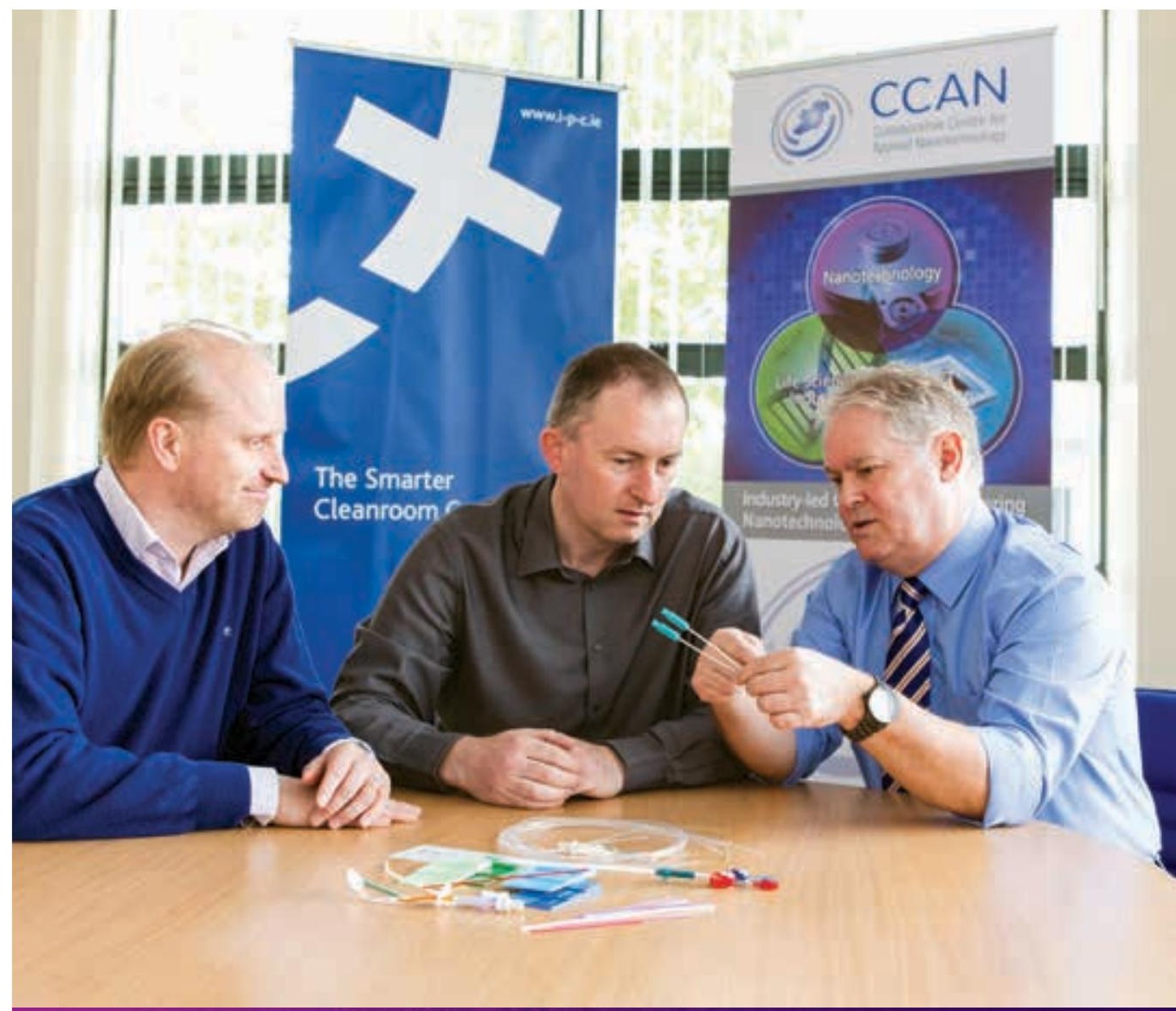

Henrik Bjoerk (left) and David Howard, IPC Sales \& Marketing Director (right) demonstrate products containing PEBASlide to Alan Hynes, CCAN Director

\section{4 success story:}

\section{New IP makes a material difference}

Kilbeggan-based Innovative Polymer Compounds (IPC) launched its PEBASlide product line at Medtech Europe in June 2014 The new range comprises Pebax polymers with reduced friction and added functionality for use in medical devices, enabling catheters and stents to be deployed into small blood vessels.

The new product line emerged from the development of new intellectual property (IP) and the granting of licences from the Collaborative Centre for Applied Nanotechnology (CCAN), which is co-hosted at Trinity and Tyndall National Institute.

IPC and Trinity initially developed strong research ties after collaborating on three pieces of research under Enterprise Ireland's Innovation Vouchers programme, with IPC benefitting from the innovation capability of Trinity researchers. When Trinity began discussions with Medtronic on a collaborative project that would require the participation of a materials supplier, Trinity introduced IPC to Medtronic and two collaborative projects were conducted with CCAN funding.

The success of these two projects resulted in IPC investing in and joining the SFI-funded AMBER Centre, hosted at Trinity. The Centre provides a partnership between leading researchers in materials science and industry to develop new materials and medical devices.

Henrik Bjoerk, co-founder of IPC, stated: "For fast growing Irish companies such as IPC to develop and deliver new products, it is essential that we can quickly and easily access the expertise needed from a wide network of development partners."

Margaret Woods, TTO manager at Trinity, said: "Trinity TTO was pleased to enhance the competitiveness of an Irish company by supporting research through to a new product release."

Added value from the university: research collaboration, intellectual property, licence 


\section{The national IP Protocol review}

$\mathrm{KTI}$ also engaged extensively with industry during the review of the national IP Protocol. The Protocol deals primarily with collaborative research, where industry and research performing organisations work together and, in particular, where industry and the State share the cost of the research. It also deals with industry access to the results of research that is $100 \%$ State funded and contract research where the industry partner pays the full cost of the research it commissions.

With the Protocol's guidance and mandate having been in place for the last two years, KTI began a review in 2014 into how the Protocol has been working in practice.

In November, $\mathrm{KTI}$ issued an open call for consultation to ascertain the key issues that have arisen since implementation of the Protocol. Responses to the call have informed a White Paper delivered to the Department of Jobs, Enterprise and Innovation in April 2015.

\section{Industry engagement}

During the year we started engaging with companies in Ireland to inform them of the value of accessing the research base, to make them aware of KTI's resources and to find out their opinions and feedback.

We participated in the Enterprise Ireland International Markets Week, Technology Gateways and Innovation Showcase events. We presented at sectoral meetings and conferences including: Ibec's Irish Software Innovation Network, the European Foundation Centre conference on research excellence held in Warsaw, the Global University Venturing Summit in London and the Intel Ireland Research Conference.
Flying the flag at the first national Innovation Showcase

Organised by Enterprise Ireland on behalf of the Department of Jobs, Enterprise and Innovation in close co-operation with IDA Ireland and Science Foundation Ireland, the event held in December was the first showcase at national level of Ireland's research and technology centres of scale and excellence. The aim of the event was to make it easy for industry to find all the information they need, in one location, on one day, to engage in collaborative research. The event also hosted the annual Enterprise Ireland Big Ideas showcase, at which 13 investor-ready start-ups presented to the Irish venture capital and investor sector.

Over 1,700 people attended, with exhibits from 38 research centres, technology centres and national research institutes and facilities which are delivering solutions for industry in six key areas: energy, food, health and medical technologies, ICT, manufacturing and materials, and services and business processes.

$\mathrm{KTI}$ and the technology transfer professionals at Irish Higher Education Institutes were on hand to showcase the range of commercial opportunities available and to demonstrate the range of opportunities available on the KTI web portal.

A national Directory of Research Centres and Technology Centres was launched at the Showcase. The directory and information on those companies that presented at Big Ideas are available on the KTI website.

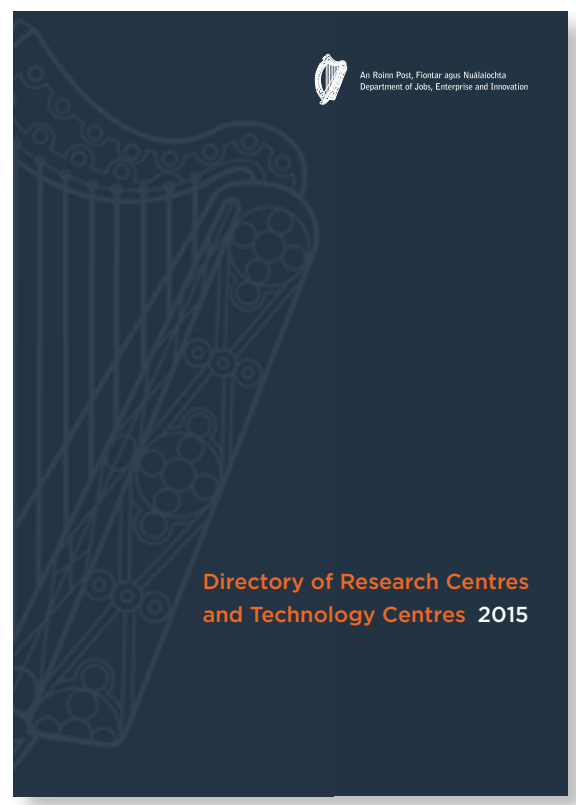




\section{Delivering returns on State investment in technology transfer}

Assessing performance under the Technology Transfer Strengthening Initiative (TTSI2) funding programme

In November, KTI managed the midterm review of the Enterprise Ireland Technology Transfer Strengthening Initiative (TTSI2) programme, a $€ 23$ million funding programme that supports the continued development of technology transfer offices within Ireland's HEls.

The objectives of the programme are:

- To sustain and develop appropriate skills within the TTOs

- To manage intellectual property

- To facilitate meaningful knowledge transfer interactions between research performing organisations and Irish industry

Progress under TTSI2 was reviewed by an international panel of eight experts in knowledge transfer. Overall, the panel was impressed by the programme and what it has been able to achieve to date. In particular, they cited the speed of evolution of the technology transfer infrastructure in Ireland and the novel approach to scaling that has been achieved in this round of funding through the creation of consortia comprising a lead and a number of partner TTOs. In conducting its review, the panel recognised the inherent challenges in the system as it evolves to cover a broader range of knowledge transfer activities. Moreover, the panel commented on the need for consortia to shift target metrics from simple measures of activity towards measuring the impacts of those activities.
In December we received a report that we had commissioned which looked at the operations of technology transfer offices within Higher Education Institutes (HEIs) and how well these are integrated into and are supported by the rest of their institution.

Overall, the review conveys the impression of a highly skilled and engaged group of technology transfer professionals, who are increasingly well integrated into their institutions, offering a range of added value services. These services include enhancing and expanding their institutions' understanding of markets, business and the commercial environment in which they operate.

The review noted that the TTOs generally provide a well-organised patenting service and are highly engaged in creating and supporting spin-outs, particularly at the earlier stages. In addition to these core activities, TTOs are heavily involved in supporting sponsored research at their institutions. The commercial know-how within the TTOs means they are actively engaged in helping their institutions to find and manage partners for research collaborations. This includes drafting and negotiating some or all of the key terms in the contracts that govern these relationships.

Many TTOs also provide a range of services to support tenants within their incubators, including introducing business partners, advising on IP issues and funding, and supplying general business support services.

The review also identified a number of specific things that could further improve and accelerate the process of integration. In particular, seizing opportunities for the research support offices in HEls and other internal departments to assist TTOs to an even greater extent, and reviewing the arrangements for supporting consultancy in HEIs. KTI will be taking these issues forward for further consideration in conjunction with the HEls and Enterprise Ireland.

\section{Evaluation of the TTSI1 funding} programme

A comprehensive review of the results from the first round of State funding of the technology transfer system across Ireland was published by $\mathrm{KTI}$ in May 2014 . The $€ 30$ million investment in the Technology Transfer Strengthening Initiative (TTSI1) ran for six years between 2007 and 2012. The review showed that by the end of the programme the average number of licences, options and assignments executed each year was up over seven-fold and the average number of spin-out companies created each year had risen by nearly $450 \%$.

The review included an independent study involving a sample of 65 Irish companies that had been able to access technology, IP and expertise from the Irish research base. The study identified that these companies had created or retained 1,844 jobs which they believed were directly attributable to their ability to engage with the higher education institution ( $\mathrm{HEI}$ ) through the technology transfer office (TTO). As a result of the programme, these companies expect to retain or create a further 2,128 jobs by 2017. 
First Annual Knowledge Transfer Survey 2013

In October, KTI published the Annual Knowledge Transfer Survey 2013 (AKTS 2013). The first report of its kind in Ireland, it illustrated the performance of the knowledge transfer system in Ireland using data returned to KTI by Ireland's 26 research performing organisations (universities, institutes of technology and State research organisations). AKTS 2013 allowed further probing of the system's performance but overall indicated that national performance in knowledge transfer is healthy. The AKTS 2014 results can be found in the second half of this report.

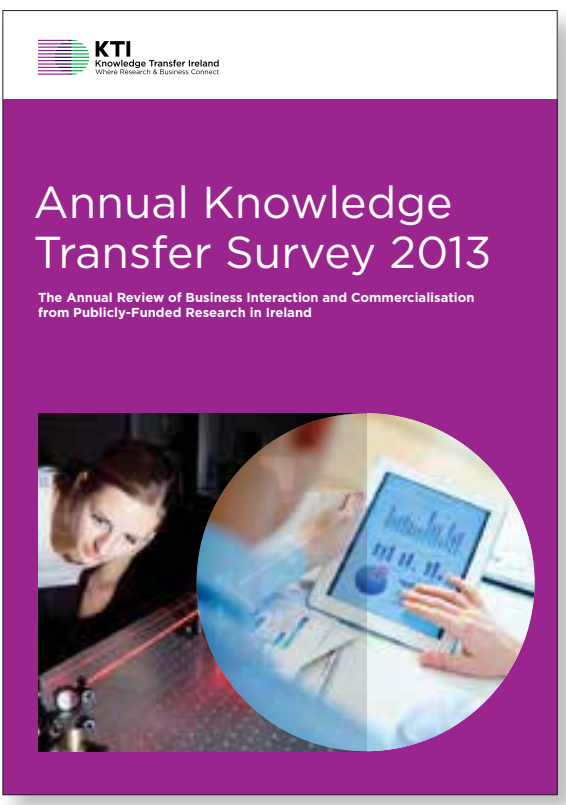

\section{Celebrating knowledge transfer and industry success}

The inaugural KTI Research2Business award was presented to Dr. Mark Southern of the University of Limerick in May. The award was used to highlight the importance for companies to engage with research performing organisations and the value these collaborations can bring to business and the economy.

The award was in recognition of Dr. Southern's and his team's sustained engagement with industry that has delivered significant impact for business in Ireland, particularly the decisions that companies were able make as a result of collaborating. These collaborations have not only led to new technology development and sales but also enabled one company to consolidate its R\&D base in Ireland, which has led to the creation of over 100 new high-end manufacturing jobs in Ireland.
There was further endorsement for UL's contribution to Knowledge Transfer later in the year when Professor Mark Davies was elected a Fellow of the American National Academy of Inventors (NAI). Election to NAI Fellow status is a high professional distinction accorded to academic inventors who have demonstrated a prolific spirit of innovation in creating or facilitating outstanding inventions that have made a tangible impact on quality of life, economic development, and the welfare of society. Professor Davies is the second University of Limerick staff member to be elected following the election earlier in 2014 of UL Vice President Research, Dr. Mary Shire. UL was the first Irish University to become a member of the Academy in June 2014. 


\section{Developing the knowledge transfer community}

In October, KTI held the inaugural Knowledge Transfer Community Forum, the first in a series of events designed to cover key issues in knowledge transfer and commercialisation of research.

The event looked at how to create successful spin-out companies and negotiate the right investment.

The audience included technology transfer professionals from Ireland's universities and institutes of technology as well as investors, entrepreneurs and academics.

A discussion on What Investors Want and Why was followed by a case study on Stokes Bio, founded by Mark Davies and Tara Dalton whilst conducting research at the University of Limerick.

Two companies shared their stories of launch and investment, and the facilitatory role that the TTO played in the spin-out process. A panel of investors and technology transfer directors explained their key drivers and supplied their tips for creating successful spin-outs.

Right: Tony Hickson of Imperial Innovations
Investors were clear that they are looking for strong management teams, considered key to creating successful spin-out companies. They also seek spin-outs that are delivering disruptive technologies. These technologies need to be protected with good IP and address real needs in the market. Investors acknowledged that Technology Transfer Offices (TTOs) should be recognised as an integral part of the value creation process.

Keynote speaker, Tony Hickson, managing director of technology transfer at Imperial Innovations, shared insights from his distinguished career in technology transfer. Imperial Innovations is an unusual hybrid of venture capitalist and technology transfer office focused on IP and spinout formation, affording him a unique perspective on creating companies from both the TTO and investor angles. He challenged the technology transfer audience to think more from an investor perspective when developing commercial propositions and encouraged simplicity in dealmaking.

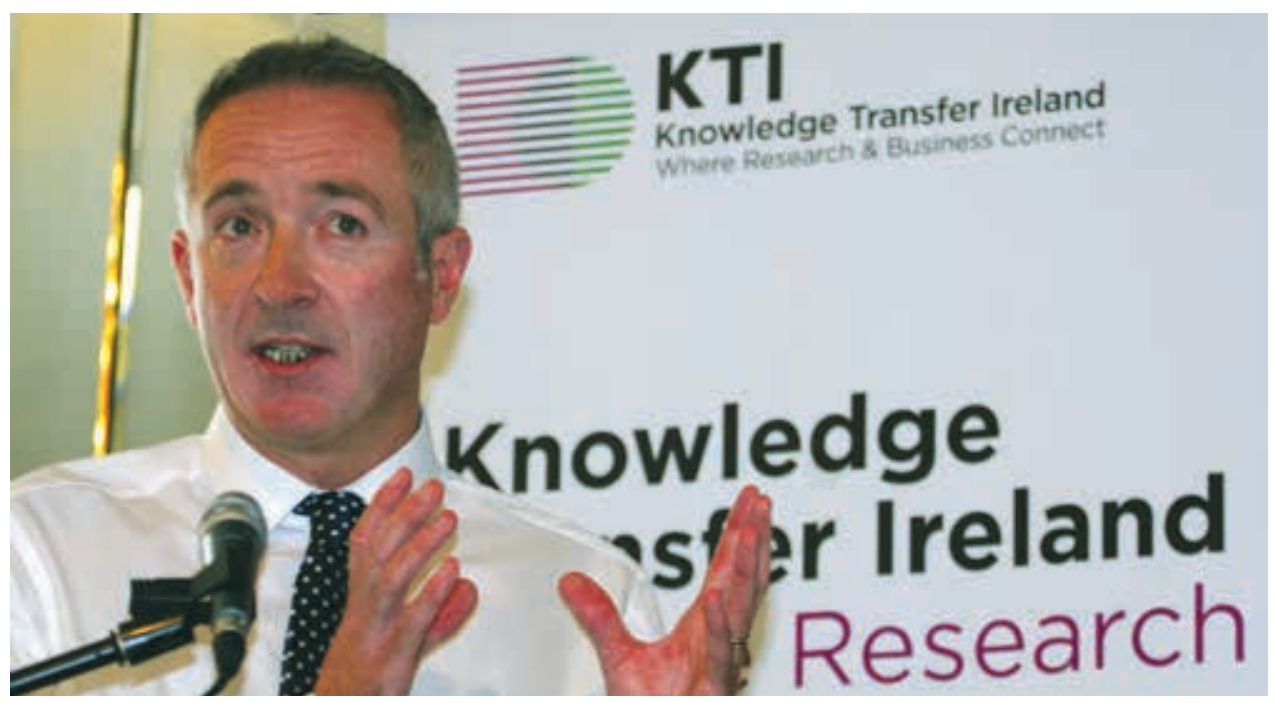


Translational research: making an impact for industry and society
In 2005 UL researchers Professor Mark Davies and Dr. Tara Dalton formed Stokes Bio Ltd to commercialise their patented UL research work on high throughput microfluidic polymerase chain reaction (PCR) technology. Stokes Bio raised in excess of US $\$ 4$ million in venture capital and in 2010 the company was sold to Life Technology Corp for US\$44 million. The trade sale provided financial returns to the University which were used to support the development of a new University of Limerick Nexus Innovation Centre. At the time of the Stokes Bio acquisition by Life the company employed 45 people many of whom were former PhD students from the University of Limerick. Professor Davies returned to the University in 2012 where he continues researching and teaching. His current research in cell-based screening has led to four new patent applications and his intention is to bring these new technologies to the market. Professor Davies shared his experiences on unpacking spinout company formation at the KTI Community Forum in December.

Added value from the university: intellectual property, licence, spinout company creation, research collaboration

\section{4 success story:}

Licence to IP from research collaboration with two HEls underpins ProPhotonix' laser technology
LED and laser company ProPhotonix agreed an exclusive, worldwide licence agreement in 2014 with Tyndall National Institute at University College Cork and Cork Institute of Technology (CIT). The licence agreement covers technology that was developed through Enterprise Ireland's Innovation Partnership Programme by the Centre for Advanced Photonics \& Process Analysis (www.cappa.ie) at $\mathrm{CIT}$ and the Photonics Packaging Group at Tyndall.

ProPhotonix designs and manufactures LED illumination systems and laser diode modules. It has operations in Ireland and the UK with its headquarters for LED operations based in Cork.
The licensed technology builds on existing laser module product lines by ProPhotonix, with high output power stabilities and high quality beam profiles, using fibre optic arrays. This unique laser module has applications in the food, industrial, medical and security sectors and was launched by the company in February 2015 at the industry's leading trade show, Photonics West, in San Francisco.

"This new capability provides a platform to develop a range of innovative product solutions for our customers. The technology was developed to be 'production ready'," said Simon Stanley, managing director at ProPhotonix Ireland.

Added value from the university: intellectual property, licence, research collaboration 


\section{KTI Mission, Vision and Goals}

\section{Mission}

To support business, the public sector and the research base to maximise innovation from State-funded research by exchanging knowledge and getting technology, ideas and expertise into the hands of business and the public sector swiftly and easily for the benefit of the public and the economy.

\section{Vision}

KTI will be recognised and respected as Ireland's central point of reference for business-research base partnership and commercialisation.

\section{Goals}

1. Enabling business to leverage the commercial potential of Irish research and innovation through connecting businesses with cuttingedge research, expertise and opportunities.

2. Taking the guesswork out of knowledge transfer through providing a predictable knowledge transfer system for Ireland.

3. Supporting, developing and building the capacity and capability in the knowledge transfer system in Ireland to deliver a first class service to business and the research community. 


\section{Governance}

$\mathrm{KTI}$ is supported by Enterprise Ireland and the Irish Universities Association. We are accountable to the Department of Jobs, Enterprise and Innovation and to the presidents of the Irish universities.

\section{Industry Advisory Board 2014}

The KTI Industry Advisory Board (IAB) supports $\mathrm{KTI}$ in setting direction and reviewing our activities. Our advisors are industry and investment professionals with experience of working with the academic research base.

\section{Members}

Karl Flannery, (Chair)

Storm Technology

Eadaoin Collins

Department of Jobs, Enterprise and Innovation

Mike Devane

American Chamber of Commerce Ireland

\section{Barry Kennedy}

Intel, ICMR, i2e2

\section{John O'Sullivan}

ACT Venture Capital

\section{Alan Phelan}

SourceDogg

\section{Dr. Ena Prosser}

Fountain Healthcare Ventures

\section{Dr. Malcolm Skingle CBE}

GlaxoSmithKline

\section{Knowledge Transfer Stakeholder Forum 2014}

The Knowledge Transfer Stakeholder Forum (KTSF) represents the major contributors to the knowledge transfer agenda in Ireland. The KTSF meets with KTI to consider issues and initiatives with the aim of developing a shared and consistent knowledge transfer system in Ireland.

\section{Members}

Enterprise Ireland Gearóid Mooney, (Joint Chair)

Irish Universities Association Ned Costello, (Joint Chair)

Department of Agriculture

Food and the Marine

Richard Howell

Department of Jobs,

Enterprise and Innovation

Eadaoin Collins

Health Research Board

\section{Dr. Graham Love}

Higher Education Authority Muiris O'Connor

\section{IDA Ireland Leo Clancy}

Institutes of Technology Ireland, (Chair), Athlone Institute of Technology

Paul Killeen

Irish Research Counci Dr. Eucharia Meehan

Irish Technology Transfer and Innovation Group, (Chair), Dublin Institute of Technology

Tom Flanagan

Science Foundation Ireland

Dr. Dara Dunican 


\section{The Team}

At KTI we come from diverse backgrounds. Some of us have worked in senior roles in industry, others bring years of experience in the knowledge transfer sector or public administration. We combine our complementary experience with a shared passion for responding to and meeting the needs of our stakeholders.

\section{Contact}

At $\mathrm{KTI}$ we welcome an open dialogue with all our stakeholders. To talk to us and to find out more about our work:

\section{Email:}

kti@knowledgetransferireland.com

Web:

WWW.knowledgetransferireland.com

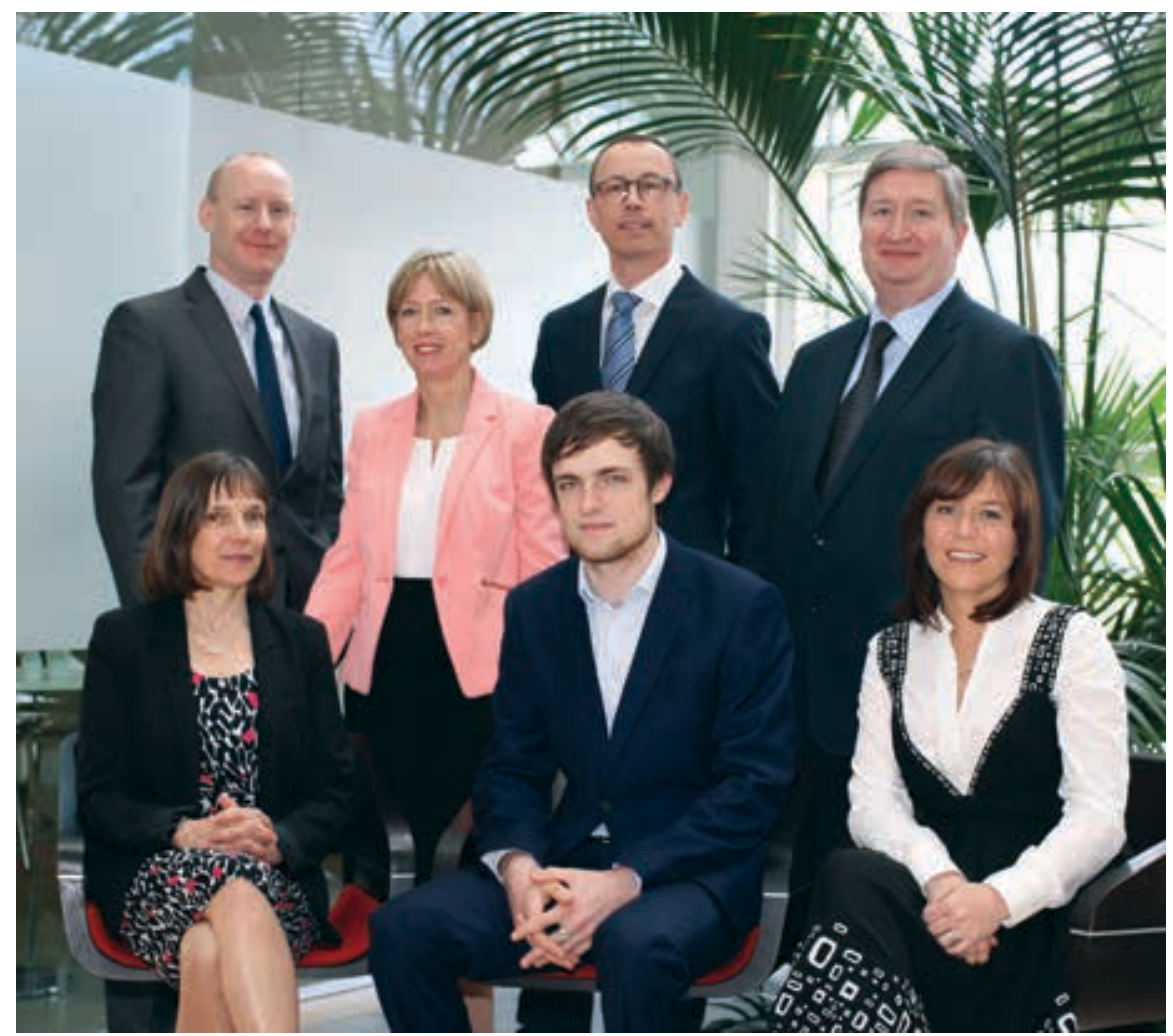

Pictured, standing from left to right:

Barry Fennell, Senior Executive; Dr. Alison Campbell, Director;

Séamus Coogan, Marketing Support; Peter O'Fegan, TTSI Operations Manager; Seated: Susan Hanna, TTSI administration; Patrick Biggar, student intern; Desirée Breslin, Senior Executive. 


\section{Annual Knowledge Transfer Survey 2014}

The annual review of business interaction and commercialisation from publicly-funded research in Ireland

HEA| HIGHER EDCATION AUTHORTYY

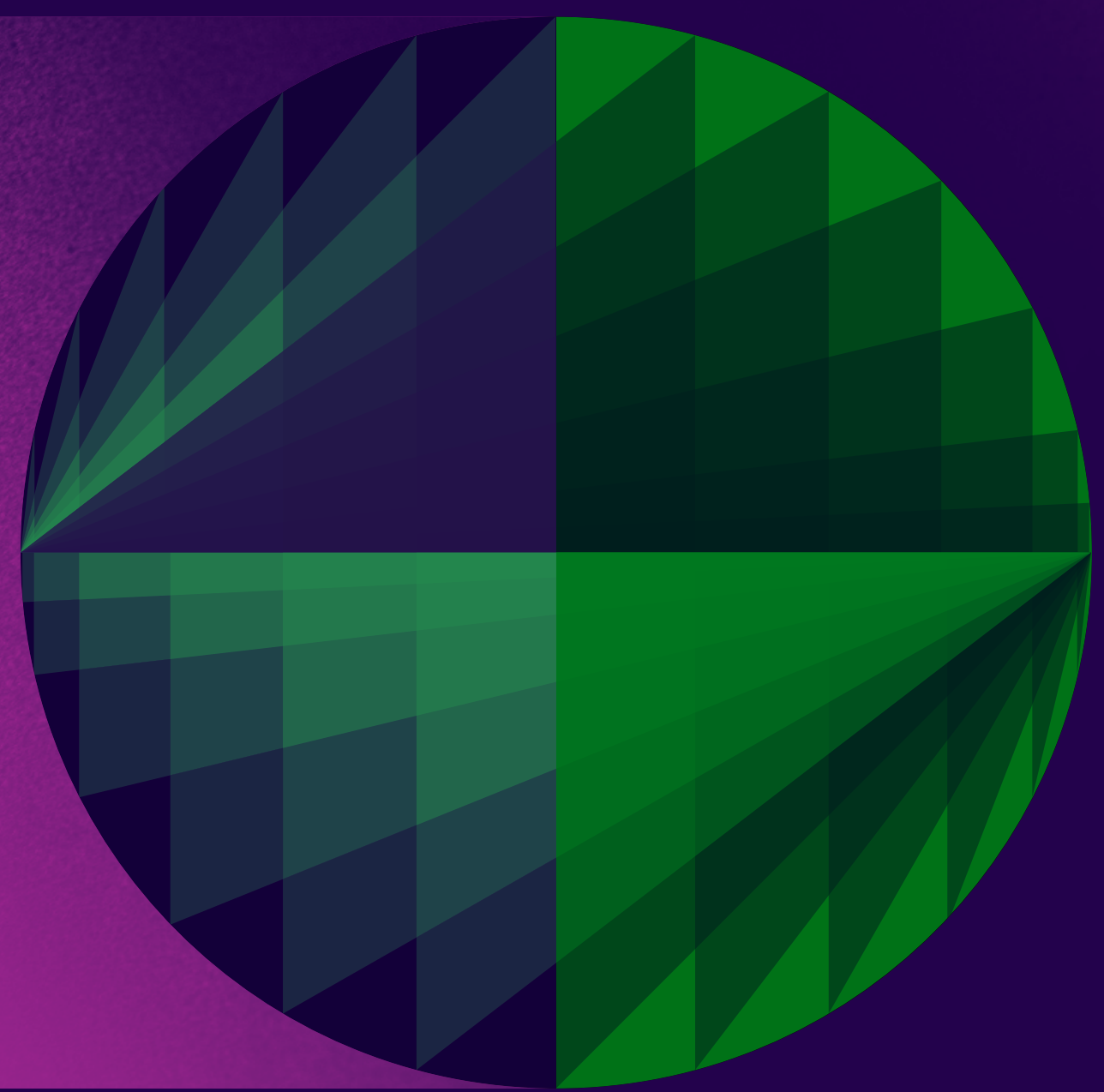




\section{Executive summary}

The Annual Knowledge Transfer Survey (AKTS) is a review of business engagement and commercialisation activity (knowledge transfer') from Ireland's State-funded research performing organisations ${ }^{2}$ (RPOs). This is the second time that this annual survey has been published and this year it is collected in conjunction with the HEA.

The purpose of knowledge transfer from the research base is to maximise the flow of technology, IP and ideas into companies and the public sector to bring products and services to the market for social and economic benefit. Many of the positive impacts of knowledge transfer cannot be captured by simple quantitative measures alone. While this report contains some examples of business impacts, more information is available in the Review of the Performance of the Irish Technology Transfer System 2007-2012 (May 2014) and in the case studies - both of which may be found on the KTI website at www. knowledgetransferireland.com.

The AKTS 2014 presents data for the period 1 January - 31 December 2014. A number of improvements were made to data collection in the 2014 AKTS including broadening the range of some of the indicators and removing those that were of limited use. The survey captures activities relating to the flow of ideas,

expertise and technologies from within the RPOs out to business.
The RPOs comprise Ireland's seven Universities and 14 Institutes of Technology; three specialist research institutes: the Royal College of Surgeons, the National College of Art \& Design (NCAD) and the National College of Ireland ( $\mathrm{NCl}$ ); and the State research bodies: the Marine Institute and Teagasc. A complete list of RPOs is provided in Appendix 2.

This year 23 RPOs responded to the survey, undertaken on behalf of Knowledge Transfer Ireland by Insight Statistical Consulting. Three institutions ${ }^{3}$ were unable to provide returns within the required time frame. There were 26 respondents in AKTS 2013

The main contact at the RPO for the purpose of this survey was its technology transfer office $\left(\mathrm{TTO}^{4}\right.$. The survey required other departments in the RPO to support the TTO in providing data. These were mainly the Research Office and the Finance Department. This placed a significant burden on the TTOs in coordinating the returns. Some RPOs could provide only a partial return as they do not have the systems to capture all of the requested information. Where certain data were not provided by an RPO, this is flagged in the relevant sections of this report. For next year's survey, KTI will work with the HEA to decide whether the AKTS data return should be requested from a different part of the RPO, such as the Finance Department. 
This report highlights a range of ways in which RPOs support the innovation ecosystem and in particular the ways in which research and expertise is shared and developed with, and by, business. This by no means covers the full gamut of innovation support within the RPOs, which also provide talent development, for instance, in many forms, including entrepreneurial training and work placements.

This year the report begins to capture information on "noncommercial" entities that work with the RPOs. Frequently these organisations are within the public or charitable sectors. The volume of engagement with these noncommercial organisations across the types of interactions captured in this survey tends to be low. This may be due to less use being made of the innovation potential in the research base by the public sector and the fact that information on these engagements may not be routinely recorded. Mapping such engagements often rests with the Research Office and/or takes place by way of consultancy activity that may be undertaken directly by the researcher with the client. In both cases the data may not be readily available to the TTO (which has been the lead entity in the RPO for completion of this survey).

Information reported in this survey spans the process of intellectual property commercialisation from invention disclosure through protection to licensing. It describes the level of business engagement with RPOs as evidenced through: collaborative research; contract services; consultancy and use of RPO facilities and equipment.
Twenty-three of Ireland's RPOs reported combined expenditure on research in 2014 of $€ 513$ million (three organisations did not respond to the survey this year). The RPO sector entered into research agreements with 1,371 different companies, executed 2,337 new collaborative research, contract research and consultancy agreements, and signed 168 LOAs.

The AKTS 2014 captures outputs from knowledge transfer such as products on the market derived from licensing from an RPO and revenue returns to the RPO. The report provides further detail on products whose launch was reported in the AKTS 2013. There is a time lag between licensing by an RPO and the licensee companies bringing new products and services to the market. In 2014, 30 new technologies that had previously been licensed out by an RPO were launched on the market by licensees.

The report looks at the volume of spin-out companies created and those surviving beyond their first three years, including further information on those "active spinouts" reported in the AKTS 2013. The survey begins to collect data on start-up companies (staff or student ventures that are not based on RPO IP). These data are not routinely recorded within RPOs and most of the information available relates to start-ups that the TTO has advised or that are based in the RPO's incubator. During 2014, 27 new spinout companies were created from within RPOs.
The report starts to assess the longer-term viability of spin-out companies. In 2014, the sector reported 97 active spin-outs from RPOs. These are companies, which are at least three years postincorporation, that have drawn on IP and expertise from the RPO and in which the RPO may have taken a founding equity stake. Active spinouts have at least one paid employee and have raised investment and/ or have booked sales revenue. The AKTS also reports on the review of active spin-outs declared in the 2013 survey, which collectively employ over 660 people.

The role of the TTOs is broad and the demands on their time and expertise ever increasing. TTOs support RPOs across a wide range of activities including seeking and/ or managing research contracts from government organisations and negotiating contracts with industry relating to collaboration, consultancy, contract services and CPD. TTOs also assist with evaluating new intellectual property, IP protection and management, licensing, spin-out company creation, managing incubation facilities, student enterprise training and building KT networks.

$\mathrm{KTI}$ wishes to thank the Technology Transfer Offices and Industrial Liaison Offices in the RPOs for their contribution to this survey and in particular their co-ordination within their RPOs to provide data across the expanded range of indicators.

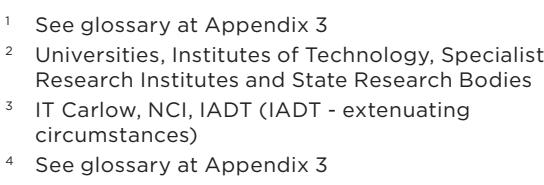




\section{Research funding in Ireland}

Figure 2.1:

Research expenditures

by RPO type, 2014

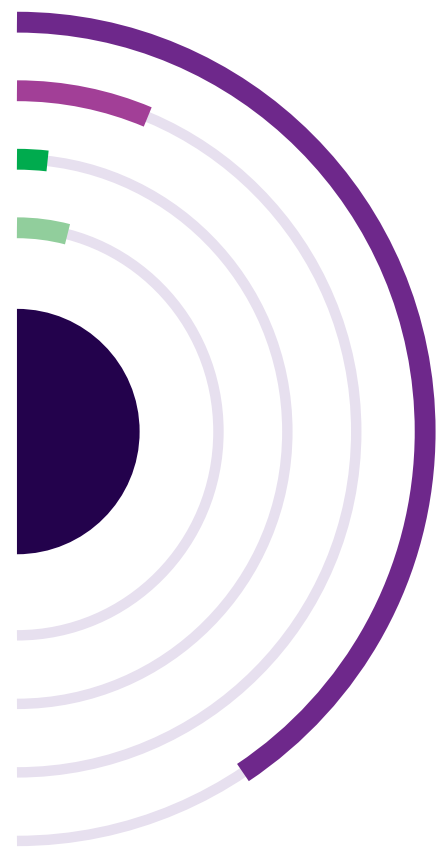

ABOVE

University

$€ 389.5 \mathrm{~m}, 76 \%$

Institute of Technology $€ 64 \mathrm{~m}, 12.5 \%$

Specialist Institute $€ 16.2 \mathrm{~m}, 3 \%$

State Research Body $€ 43.7 \mathrm{~m}, 8.5 \%$

Ireland's total investment in Higher Education R\&D (HERD) is published by Forfás, Ireland's policy advisory board for enterprise, trade, science, technology and innovation. The latest (provisional) figure available for HERD is $€ 732$ million for 2011.

The total research expenditure (less block grant) for 2014 was provided by the RPOs from their Finance Departments. It is approximately $€ 513$ million, up $6 \%$ on 2013 . This represents the total expenditures on all types of basic and applied research in Irish RPOs from all funding sources: government, industry, non-profit foundations, etc. It excludes any academic costs dedicated to research, costs of administrative support and capital expenditures on new equipment, buildings or land. The proportional spread of expenditure across RPO types is similar to last year. However, one of the three specialist institutes $(\mathrm{NCl})$ and two of the 14 IoTs (IADT and IT (arlow) did not return data.
From Figure 2.1, the University sector accounted for the majority of all research expenditure at $76 \%(€ 390 \mathrm{~m})$. The Institutes of Technology sector accounted for $12.5 \%$ ( $€ 64 \mathrm{~m}$ ) of the State's expenditure on research. The Specialist Institute sector (RCSI, NCAD) spent $€ 16$ million on research (3\%) and the State Research Bodies (Marine Institute and Teagasc) accounted for $8.5 \%$ ( $€ 44 \mathrm{~m}$ ) of research expenditure.

In total $6 \%$ of research expenditure was related to research revenue from the private sector, which is low by international standards. The majority (65\%) derived from government funding sources and a further $18 \%$ came from the EU.

On average, the percentage of research expenditure by universities derived from private sector sources ranged from $2.7 \%$ to $12 \%$ with an average of $7 \%$ which was down on the previous year's average of $8 \%$. In contrast, the Institutes of Technology average was $9 \%$, up from $7.2 \%$ in 2013 , and the range was $0-32 \%$. 


\section{Business access to research and expertise within Ireland's RPOs}

\author{
One of the principal ways that business benefits from \\ working with RPOs is through access to research and \\ expertise. This is most frequently through three different \\ categories of engagement:
}

1. Collaborative research programmes are where the RPO and company (or non-commercial entity) jointly develop the work plan. Funding may be solely from the third party but is likely to involve some level of co-funding from government sources.

2. Contract research projects are where the company specifies the work to be undertaken by the RPO and pays all the costs of the work programme. This includes agreements that may involve a "work order" or may be considered as "contract services".
3. Consultancy involves the RPO providing advice and assistance to a company (or noncommercial entity). This work does not require new research activity and is usually fully funded by the company.

The AKTS is a vehicle to assist the State to gain a deeper appreciation of the ways in which business (and other non-commercial "users" of research) interact with the research system in Ireland. As the definitions indicate, these engagements involve quite different ways of working and each has its merits and benefits to enterprise. Historically these types of engagement have been lumped together as "collaborative research".
The RPO survey respondents are now able to differentiate between these kinds of interactions, except for the University of Limerick which is unable to disaggregate data.

The total number of research (collaboration and contract) and consultancy agreements executed in 2014 was 2,337. The total number of each type of agreement entered into by the relevant groups of RPOs (excluding the University of Limerick ${ }^{5}$ ) in 2014 is illustrated in Figure 3.1 which demonstrates a propensity for contract research. The high figure for consultancy contracts in the State Research Body sector reflects its focus on providing and tracking its consultancy offering.

Figure 3.1:

Number of research and consultancy agreements in 2014 by RPO type

NUMBER OF AGREEMENTS

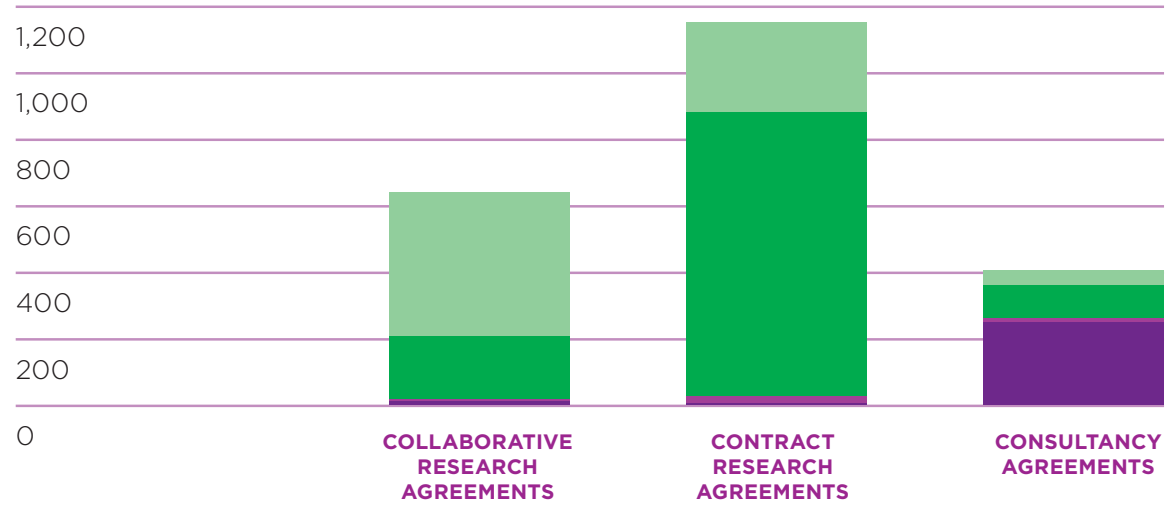




\section{Kildery Cheese}

\section{Collaboration at its best}

Cheese has been targeted by Teagasc and the Irish Dairy Board as a vital end product for the increased milk pool likely to arise as milk quotas end, because demand for cheese is growing worldwide.

In 2014, Kildery, a Maasdammerstyle cheese, was launched as a new Irish continental-style branded cheese in Germany. It was developed at the Teagasc Food Research Centre, Moorepark, Fermoy and in collaboration with Tipperary Co-operative Creamery and the Irish Dairy Board (IDB), under the Kerrygold brand.

Manuel Rodriguez-Eicke, marketing director, Kerrygold, Germany, said: "Kerrygold Kildery Cheese brings Kerrygold into the mainstream Maasdam category, the largest branded cheese category in Germany."

This successful collaboration was based on the significant expertise of Teagasc in cheese technology. Pilot scale to commercial scale development was undertaken at the Moorepark Technology pilot plant facility.

"This resulted in the development and refinement of prototypes, which underwent technology transfer to commercial scale. In commercial scale trials, technologists from Teagasc, the IDB and Tipperary Coop combined their diverse areas of expertise to optimise the production and ripening processes resulting in Kildery cheese," said Dr. Diarmuid Sheehan, research scientist and cheese programme manager at Teagasc's Dairy Innovation Centre.

The collaboration drew on IDB expertise in market distribution/ global sales and production and the scale-up capabilities of Tipperary Co-op. With increased exports of Irish dairy products there will be some financial payback to Teagasc based on agreed royalties on sales, which will be reinvested into the food research programme.

\section{Added value from the research} institution: research collaboration

\section{Photograph: Ornua}

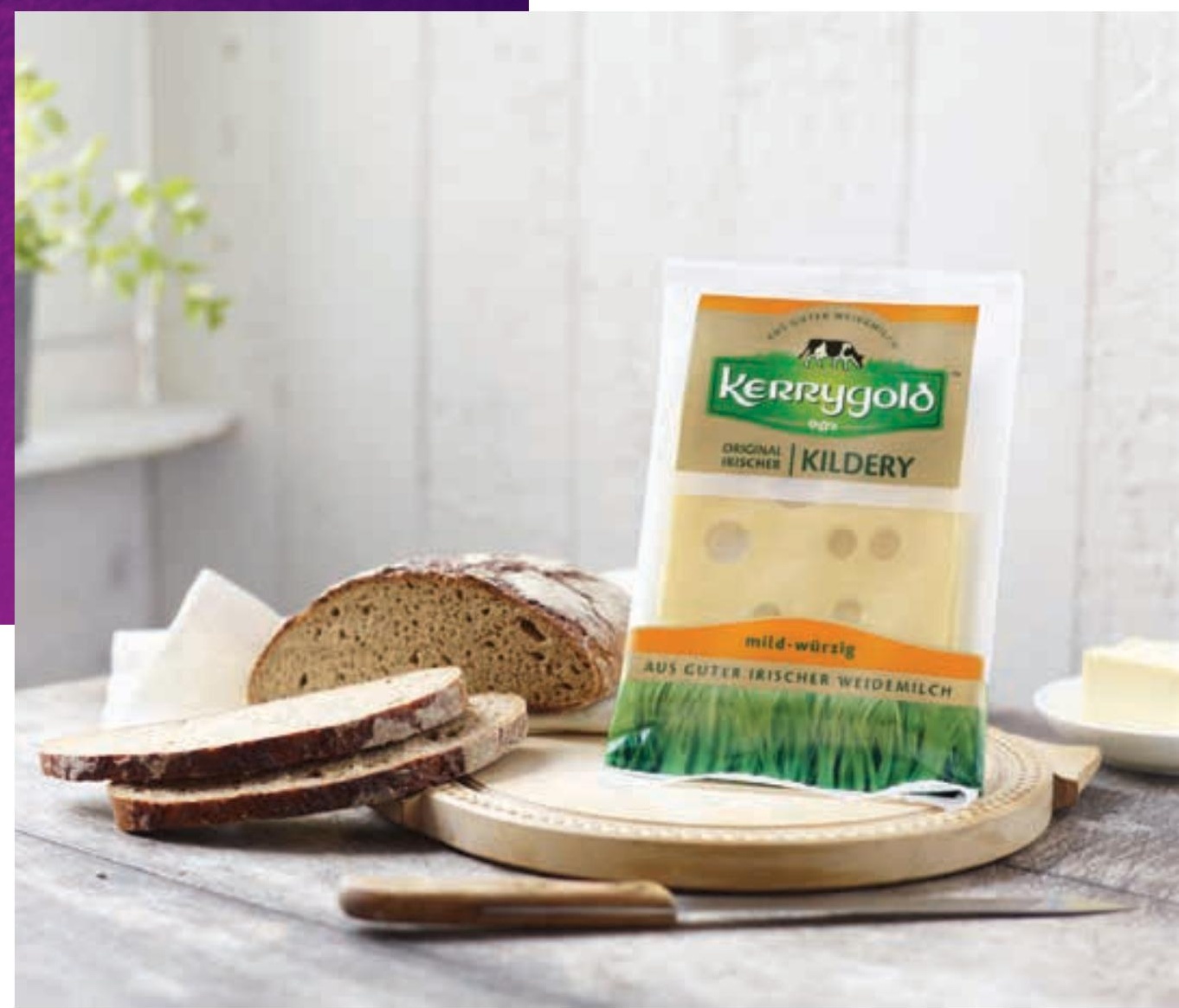




\subsection{Working with Irish companies}

From the information provided on company location 6 , $67 \%$ of companies with whom the RPOs have executed a research agreement are based in Ireland. 92\% of engagements with SMEs are with Irish SMEs and $44 \%$ of engagements with MNCs are with Irish-located companies. In addition, there were a handful of collaborative or contract research agreements executed with large Irish companies or with High Potential Start Up companies (HPSUs).

\subsection{Research with business}

Technology transfer offices (TTOs) ${ }^{7}$ worked with nearly 1,371 different companies on collaborative or contract research programmes as determined through the research agreements signed in 2014. This was up by $46 \%$ on the previous year. A further 250 companies were repeat engagements within the past three years.

\subsubsection{Collaborative research with business}

The total number of collaborative agreements executed by the RPOs in 2014 was 647 and this is mainly accounted for by the University sector (excluding $U L$ which is unable to disaggregate data) with 440 agreements (68\%). Results indicate that $58 \%$ of collaboration agreements signed by RPOs in 2014 were with Irish companies ${ }^{8}$.

\subsubsection{Contract research projects}

In 2014 1,163 contract research agreements were signed, an increase of $178 \%$ since 2013 . This sharp increase may in part be due to the detail in the definition of contract research which enabled more of the valuable ways in which RPOs work with industry to be included. For example, including "work orders" in the definition was helpful for some IOTs. There were nearly twice as many contract research projects $(1,163)$ as research collaborations (647) undertaken by RPOs and the Institute of Technology sector undertook the majority of these arrangements (861 agreements, $74 \%$ ). $74 \%$ of contract research agreements were signed with Irish companies ${ }^{9}$.

Figure 3.2:

Location of companies with whom the RPO has executed a research (collaboration or contract) or consultancy agreement 2014

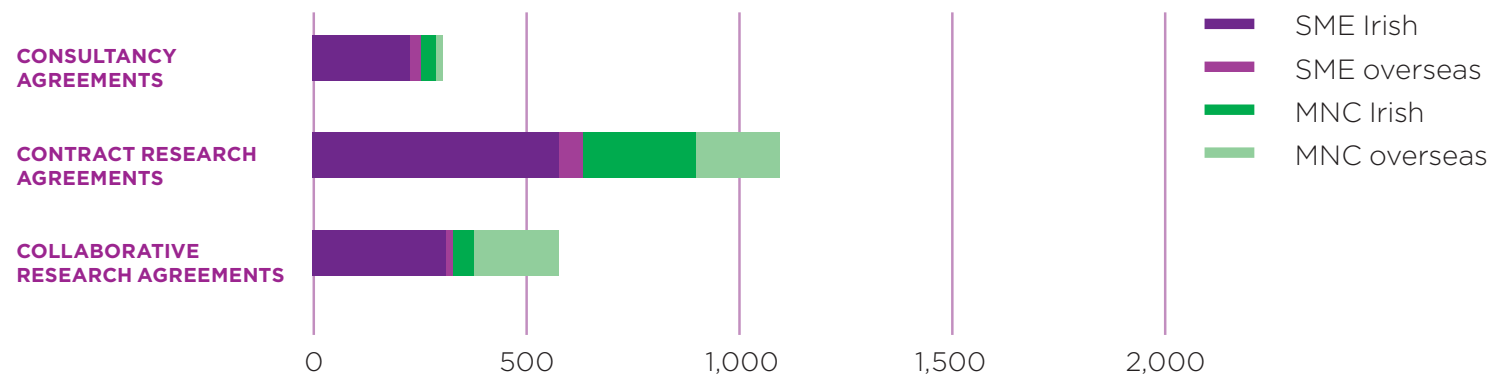

\footnotetext{
Data not provided by University of Limerick (UL) IT Carlow, IADT, NCI

Data not provided by IT Carlow, IADT, NCI

3 Data not provided by University of Limerick (UL), IT Carlow, IADT, NCI

9 Data not provided by University of Limerick (UL), IT Carlow, IADT, NCI
} 


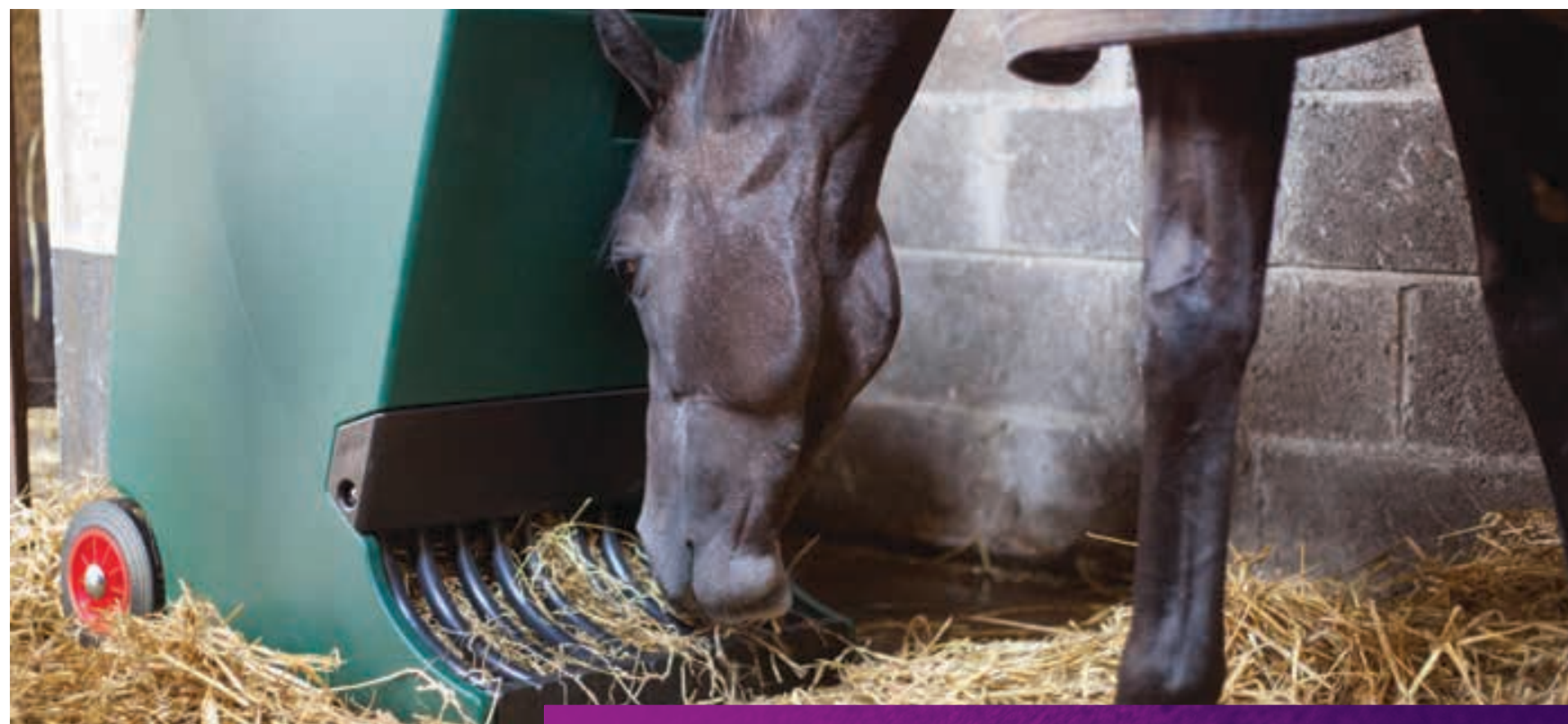

Harmony hayfeeder - Equiniche

\section{Equiniche Sciences}

Collaborative research reaps innovation award and global sales

Equiniche Sciences, founded by veterinary physiotherapist $\mathrm{Dr}$. Michelle O'Connor, engaged in collaborative research with the Centre for Industrial Services and Design (CISD) at Athlone Institute of Technology (AIT) to bring to market its Harmony Equine Hay Feeder, which allows horses to eat in an anatomically comfortable position CISD helped with the design and development of a prototype of the hay feeder in collaboration with two manufacturers.

The Harmony Equine Hay Feeder was launched at the Equus Live Exhibition in Punchestown in November 2013 where it won the inaugural Innovation Award. The product has since generated ongoing sales in Ireland, the UK and Germany.

"Materials selection, various moulding technologies, 2D and 3D product and tooling design, entrepreneurship supports and startup advice were all part of Michelle's engagement over a two year period," said Breda Lynch, Industry Programmes Manager at AIT.

"We worked hard to ensure the contracts - in this case relating to two innovation vouchers - were user friendly. We revised them based on feedback from clients, and always in line with the national IP protocol and Enterprise Ireland funding guidelines," said Lynch.

Michelle O'Connor said that Conor Hayes from the CISD brought the hay feeder from concept to prototype to final design for manufacture and provided a means of visualising the product as it progressed through development from concept to reality.

"Conor not only has clear technical know-how and expertise in design but produced an aesthetically pleasing product with unique design features which has been recognised by our customers," said O'Connor.

Added value from the Institute of Technology: collaborative research 


\subsection{Consultancy to business}

The number of consultancy agreements remained relatively static between 2010 and 2013 with 527 being concluded in 2013 by 14 of the 26 RPOs $^{10}$. In 2014, only 407 consultancy agreements were reported and Teagasc accounted for $250(47 \%)$ of these. The Institutes of Technology accounted for $25 \%$ of consultancy agreements (102). However only five of the 12 loTs $^{11}$ that reported this year were able to show consultancy activity, which ranged from 1 to 76 contracts. Of the six universities that were able to provide data on consultancy, there were just 43 agreements signed in 2014 (10.5\%) with the range of 0-15 contracts per university.

Consultancy is a complex issue as the majority of the activity is not managed as "institutional consultancy" but handled as a direct engagement between a researcher and the client. This is due in part to current legislative frameworks. International benchmarks show that consultancy is a valued way for business to access expertise and the Irish data suggest that the RPOs are not capturing the inherent value and impact achievable through consultancy activity.

\section{Licence from Maynooth University speeds success at Code On Technologies}

The relationship between Code On Technologies and Maynooth University is based on a longrunning, productive research collaboration and a licence to patented intellectual property from the university.

\section{Professors Douglas Leith of} Maynooth University (MU) and Muriel Médard of Massachusetts Institute of Technology and Code On co-founder were working on complementary issues related to minimising network delays and congestion in a wide range of applications such as content distribution, multimedia sharing, and dense mobile networks.

Code On initially approached MU about licensing patented technology that helps manage TCP network congestion and was developed by Leith and Professor Robert Shorten at MU's Hamilton Institute. Working closely with Maynooth University Commercialisation Office, a full commercial licence for technology that increases data transfer efficiency was granted within three months over the summer of 2013.

Code On's proprietary algorithm, Random Linear Network Coding (RLNC), is a coding scheme that makes network coding practical and is a key ingredient for the Internet of Things (IOT). RLNC provides order-of-magnitude efficiency improvement wherever data is stored or transmitted and the deal with MU enhances that capability.

Managing director and business founder Laila Partridge had high praise for the MU Commercialisation Office: "Maynooth's licensing officers are experienced business professionals with a sophisticated understanding of and a focus on commercialising new technologies. Licensing discussions moved quickly and smoothly."

Peter Conlon of the Maynooth University Commercialisation Office described the negotiation as a knowledge transfer exercise in the form of patented technology and specialist, inventor-led support and consultancy and proof of concept software implementations.

"From the start Code On has been open and transparent about how it wants to do business with Maynooth University, what it wants to use our technology for and how it wants to build towards future collaborations. Maynooth University has been made feel like a partner. This has significantly eased licence negotiations," Conlon said.

Added value from the university: intellectual property, licence, collaboration, consultancy

\footnotetext{
10 Data not provided by University of Limerick (UL), IT Carlow, IADT, NCI

1 Returns not provided by IT Carlow or IADT
} 


\section{Research and consultancy with non-commercial organisations}

For the first time, the survey asked for information on other non-academic research partners and consultancy clients. These non-commercial organisations include public sector organisations, non-governmental organisations and charities. In particular, the use of research and the expertise within the RPO system by the public sector in Ireland offers a real opportunity to innovate and one which the AKTS will track over time.

Table 4.1:

Number of research and consultancy agreements executed in year with non-commercial organisations ${ }^{12}$

\begin{tabular}{|l|r|r|r|}
\hline Type & $\begin{array}{r}\text { Number of } \\
\text { contracts } \\
\text { signed }\end{array}$ & $\begin{array}{r}\text { \% of total } \\
\text { number of } \\
\text { rontracts of } \\
\text { this type }\end{array}$ & $\begin{array}{r}\text { \% with Irish } \\
\text { entities }\end{array}$ \\
\hline Collaborative research & 52 & 8 & 71 \\
\hline Contract research & 42 & 4 & 95 \\
\hline Consultancy & 87 & 21 & 90 \\
\hline
\end{tabular}




\section{Revenue from research agreements and consultancy}

This year the AKTS asked for research expenditure in 2014 related to revenue through research agreements and revenue from consultancy. This is primarily to enable international comparisons to be undertaken. The request, including breakdown of cash and in-kind contributions in respect of research agreements, caused some difficulty for a number of RPOs. Only 18 RPOs were able to answer the direct cash question for collaborative research agreements and only 16 were able to provide revenue figures for contract research.

\subsection{Total revenue from collaborative research and contract research}

At least $€ 46$ million of total research expenditure within RPOs during 2014 related to funding from the private sector. This represents approximately $8 \%$ of the total research expenditure in the year reported by $23 \mathrm{RPO}^{13}$. Direct correlation with 2013 is not possible due to the way in which the question was posed this year - actual spend during the year related to collaborative and contracts research agreements that may have been signed in 2014 or previously. In 2013 reporting may have included the value of research agreements signed in that year, such agreements being for different durations of between one and five years. The new question should provide more robust results as data should come directly from the RPO finance team and will track actual expenditure rather than potential value which may not be realised, for example, if a programme is not commenced or terminates early.

\subsection{Revenue from consultancy}

Given that consultancy is usually not run institutionally, the data returned by the RPOs is an underestimate of the value of consultancy activity from across the RPO sector. Of the 23 RPOs that returned data in the AKTS 2014, three were unable to supply financial data for consultancy. Of the 20 that did, 10 reported this to be zero. Total consultancy revenue reported for the year was $€ 5,804,421$.

Five universities reported on consultancy revenue, with one of these declaring zero. In the IOT sector, 11 of the 12 loTs returned data and, of these, seven declared zero revenue. Gross revenue for the four loTs reporting revenue was $€ 703,625$. RCSI and Teagasc also reported consultancy revenue totalling $€ 4,629,156$ with the lion's share going to Teagasc ( $€ 4 \mathrm{~m}$ ).
Figure 5.1:

Revenue from consultancy by RPO type

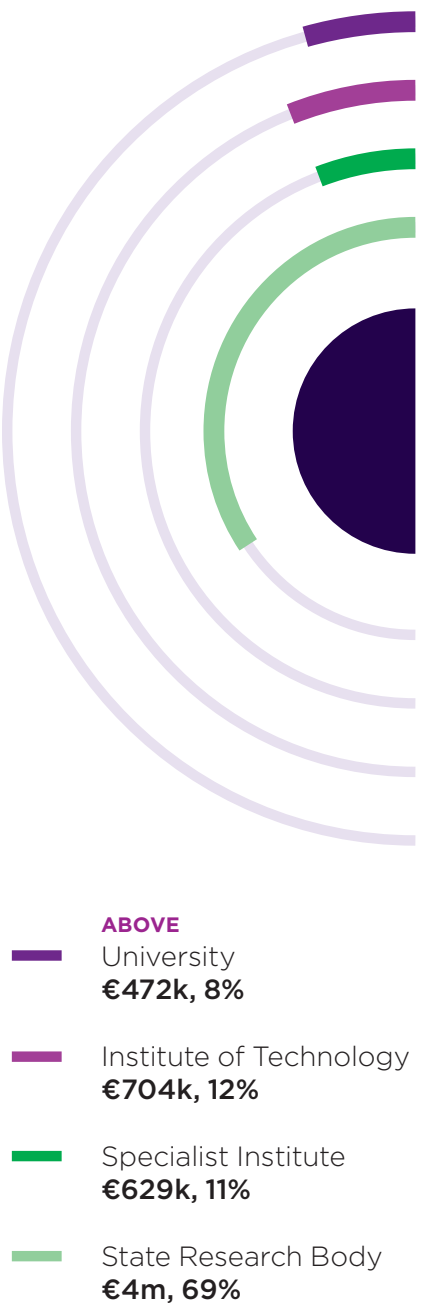




\section{Invention disclosures}

The first step in the process of commercialising a new piece of technology takes the form of an invention disclosure. The researcher discusses with the TTO a tangible discovery or development that they have made and, if merited, details are submitted in writing. The TTO undertakes a preliminary commercial assessment of the invention and, if it is accepted into the TTO system for further development, this is recorded on an Invention Disclosure Form (IDF). The IDF contains the basic information needed to evaluate the intellectual property associated with the invention and, where appropriate, to protect and commercialise it.

In 2014, there were 423 invention disclosures of which $72 \%$ (306) were in the University sector and 22\% (94) were in the Institute of Technology sector. 4\% (15) were in the State Research Body with a further $2 \%$ being made in the specialist research institutes (8). The total number of invention disclosures represented a dip of 9\% from 2013.

For the purpose of this survey, both sole and joint invention disclosures are recorded. Sole invention disclosures are those made by researchers working in only one institution and submitted only to that RPO. Joint invention disclosures are disclosures relating to the same invention where the inventors involved work for different RPOs and where each inventor has separately disclosed their invention to their employing institution. Any subsequent IP protection and commercialisation is usually undertaken by the RPO

Figure 6.1:

Invention disclosures,

$2010-2014$

NUMBER OF DISCLOSURES

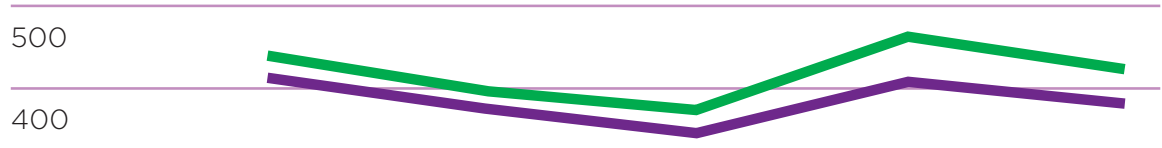

300

200

$$
100
$$

0

$\begin{array}{ccc} & \mathbf{2 0 1 0} & \mathbf{2 0 1 1} \\ \text { Sole } & 411 & 376 \\ \text { Joint } & 20 & 16 \\ \text { Total } & 431 & 392\end{array}$

2012

346

27

373
2013

404

58

462 that is best placed to lead, under an arrangement with the other RPO called an Inter-Institutional Agreement (IIA). Figure 6.1 shows the number of sole and joint invention disclosures received in 2014 and the five year trend.

As shown in Figure 6.1, 90\% of disclosures were sole disclosures (381) and $10 \%$ of disclosures were joint (42). There was an expectation that joint disclosures would continue to rise over time as more collaborative research is now undertaken across RPOs and more inter-institutional research centres have been established, which should give rise to more joint IP. It will be interesting to see how this trend develops over the next few years.

Figure 6.2 illustrates that 274 (72\%) of sole IDFs were submitted in the University sector and, of the joint IDFs, 32 (76\%) were in the University sector. This suggests that there was greater collaboration amongst University researchers leading to the generation of more joint IP from the University sector.

Figure 6.2:

Invention disclosures in 2014 by RPO type

\section{NUMBER OF DISCLOSURES}

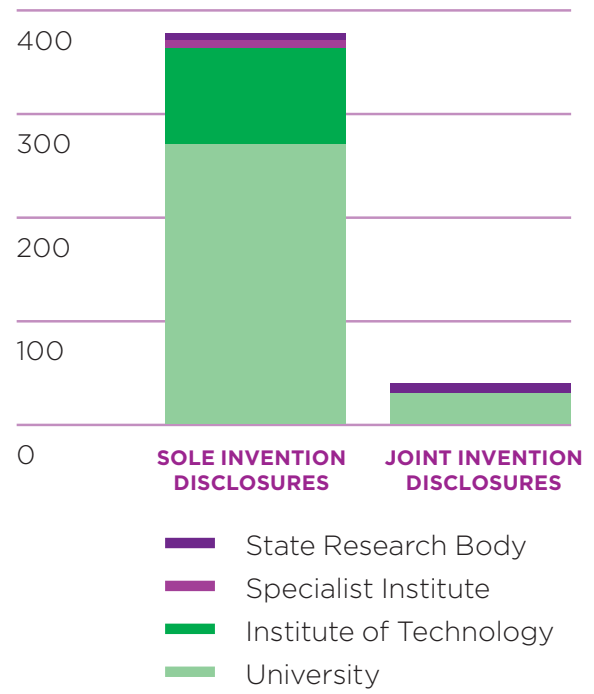




\section{Patent activity}

A patent confers upon its holder, for a limited period, the right to exclude others from exploiting (making, using, selling, importing) the patented invention, except with the consent of the owner of the patent. A patent is a form of "industrial property", which can be assigned, transferred, licensed or used by the owner. Filing a patent application with a national patent office is the first step in seeking protection for the invention and establishes a priority date for the invention.

Not all applications are filed with the Irish Patent Office as patent applicants often prefer to file direct in territories where the invention may be commercialised, or direct with the European Patent Office (EPO). Filings are also made with the UK IP Office (UK IPO) to expedite the official "search" relating to the application so that the RPO has a better understanding of patentability and claims required at the end of the priority year. This early search can also point the way to potential competitors and licensees. The results of this process give applicants greater confidence in deciding whether to pursue, abandon or alter the patent application.

\section{Alimentary Health: A culture of patent development}

Alimentary Health, a global leader in the development and commercialisation of technologies for gastrointestinal disorders, launched its new precision biotic product Alflorex in Ireland in 2014, based on a licence from UCC.

In March 2015 Alflorex was awarded Best Irish Pharmacy Product for 2015. The company has also been shortlisted in the SME/ Start-up category for the US-Ireland Research Innovation Awards which was announced in the Irish Times in March 2015.

Alimentary Health co-founder and CEO Dr. Barry Kiely said: "Alimentary Health's new and breakthrough scientific research is recognised around the world as being at the cutting edge of discovery and application of targeted strains delivering the benefit where it is needed."

Alflorex is rooted in the science of a patented and well-documented probiotic culture Bifidobacterium infantis 35624 (B. infantis 35624), first discovered in research labs at UCC during the 1990s. This technology was part of a portfolio spun out of UCC by the founders in 1999 into Alimentary Health Ltd. This spin-out process was supported by both Enterprise Ireland and the UCC Industry Liaison Office, which provided advice on licensing and technology the incorporation of the company and managing the internal approval process for the company to spin out. Subsequently Alimentary Health became a founding member of the Alimentary Pharmabiotic Centre (APC), a Science Foundation Ireland research centre based at UCC, which has received global recognition as one of the world's leading institutions in probiotic research.
Alimentary Health has had significant commercial success in global markets. In 2005 the company sub-licensed the B. infantis 35624 to Procter \& Gamble (P\&G), which today markets the strain under the brand name Align in the United States and Canada. In a product survey in 2012 Align was rated the No. 1 Gastroenterologist Recommended Probiotic in the US.

Alimentary Health has worked closely with the UCC TTO since the office was established in 2007 , including the exploration of further licensing opportunities based on technologies emanating from APC. The company has also availed of GatewayUCC incubator space during this time.

"This is an excellent example of an indigenous Irish company competing in global markets, having commercialised world-class research from an Irish university," said Dr. Tim Roche, technology transfer director at UCC. "As a founding member of APC, Alimentary Health has played a key role in commercialising the research undertaken in the Centre."

Added value from the university: intellectual property, licence, spinout company creation, company incubation, research collaboration 


\subsection{RPO patent portfolio}

The number of patent families owned by the RPOs at the end of 2014 was $585 . .^{14}$ A patent family may include patent applications or granted patents that derive from the same original filing.

\subsection{Initial patent filings}

To understand the level of new IP being protected, in cases where initial patent applications were filed for the same invention in more than one jurisdiction, only one priority patent application filed is counted in the year of application. On this basis, the number of new patent filings made in 2014 was $117^{15}$. The average total number of priority patent applications each year over the past four years has been 120 and the 2014 data suggest that the number of priority filings is reaching a steady level.

\section{Figure 7.1:}

Priority patent applications over the past five years

\section{NUMBER OF APPLICATIONS}

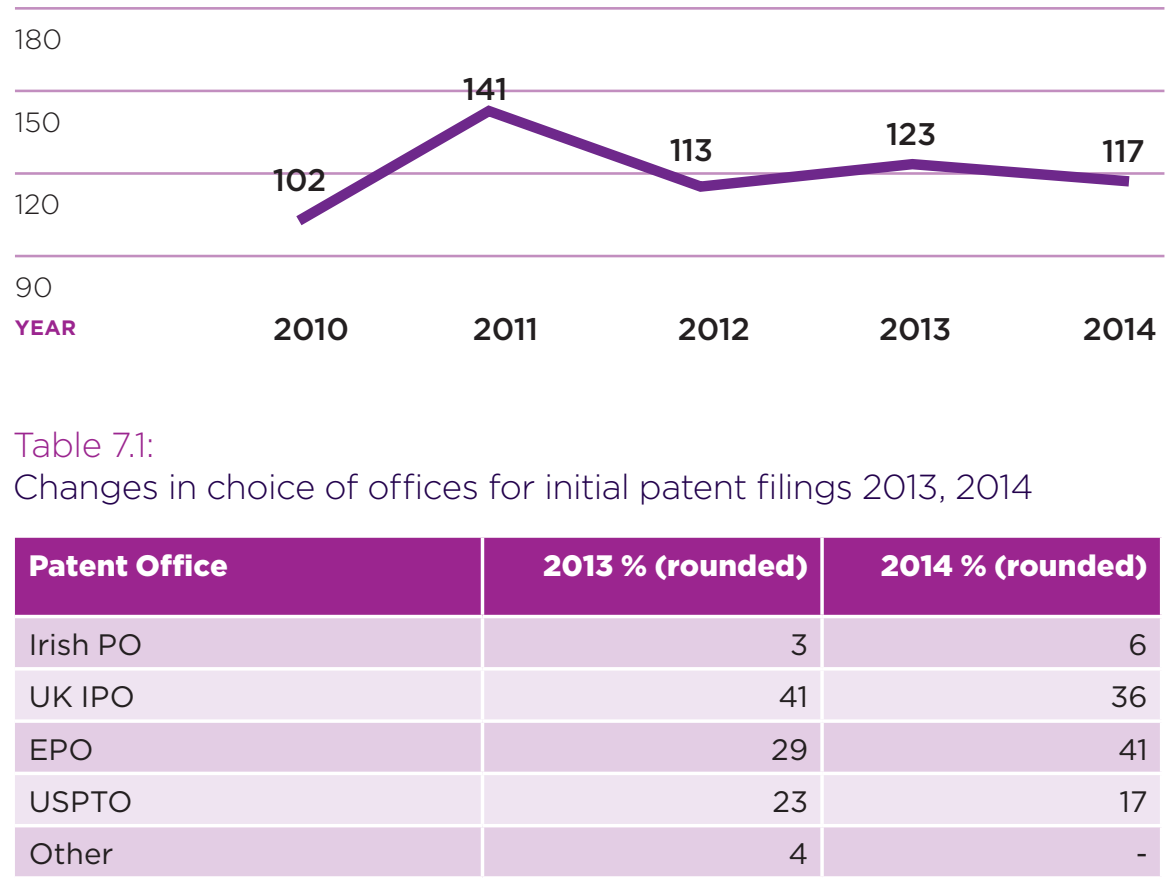

The choice of priority patent filing territories is diverse. The EPO and the UK IPO are the favoured jurisdictions with $77 \%$ of initial priority fillings made in these territories in 2014. This represents a change from the previous year as reflected in Table 7.1. At 6\%, the number of first filings in Ireland has doubled. However this represents a total of just seven filings. Figure 7.2 shows this breakdown ${ }^{16}$.

The University sector accounted for over three-quarters (77\%) of all priority patent applications made accounting for $14 \%$ of the filings made, and the remainder coming from Specialist Institutes (6\%) and State Research Bodies (3\%). This is fairly consistent with the distribution seen in 2013. by RPOs in 2014 , with the loTs
Figure 7.2:

Initial priority patent filing jurisdictions

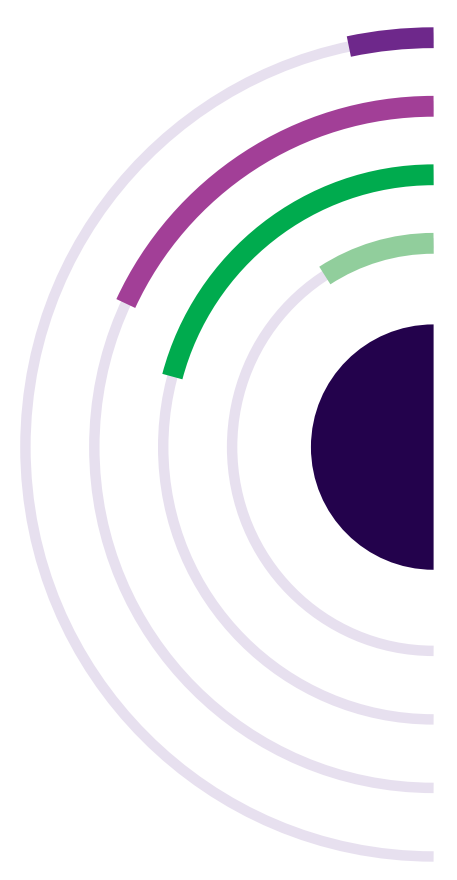

ABOVE

Irish Patent Office $6 \%$

UKIPO $36 \%$

EPO $41 \%$

USPTO $17 \%$ 
Figure 7.3:

Percentage of priority patent applications in 2014 by RPO type ${ }^{17}$

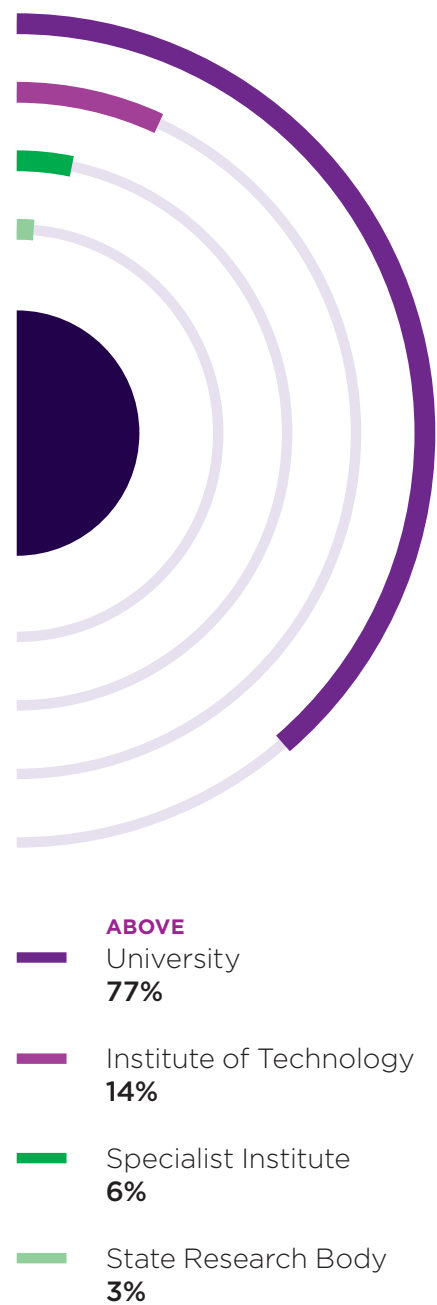

\subsection{PCT applications}

The Patent Cooperation Treaty (PCT) makes it possible to seek patent protection for an invention in a large number of countries simultaneously by filing an international patent application. The PCT application can take its priority date from an initial national filing and so a PCT application is usually made 12 months after the first filing.

There were 63 PCT filings in 2014, representing an increase of $54 \%$ on the previous year's figure of 41 . However this is $22 \%$ less than the 2012 figure of 81 PCT filings. There is little that can be read into these data alone and it is more interesting to examine the level of decisions made to progress an initial filing to PCT stage.

Of the 123 initial filings made in $2013,51 \%$ were progressed to PCT applications in 2014. This was an increase on 2013 where 36\% progressed to PCT filing. Although no PCT progression data were provided by four RPOs this year ${ }^{18}$, as only one patent application was filed amongst this group last year, and as IT Sligo failed to make a return in 2013 or 2014, the lack of patent application progression data for this group does not skew the figure above.
This increase in the proportion of filings being progressed to PCT applications suggests more confidence in the commercial potential of the initial applications than in the previous year and offsets the slight drop in initial filings made in 2014. Indeed this might be seen as a positive trend as it is often necessary (patent budget permitting) to progress patent applications further before licensing in order to grow the value and relevance to industry of early stage IP.

The range of progression from initial application to PCT amongst the RPOs was from 0-100\%. In the university sector the range was $0-57 \%$ and for the loTs $12.5-$ $66 \%$. RCSI progressed $100 \%$ of its previous filings to PCT whilst the conversion rate for Teagasc was $66 \%$.

Eighteen months after a PCT application has been filed, it must be nationalised in individual countries and regions selected from those previously designated in international applications. This is a costly procedure and patent applications are often licensed prior to this stage. Where they are not yet licensed, the RPO will only progress to this stage if the invention shows significant commercial promise. The data on national filings relate to such filings made in the name of the RPO and which may be paid for by the RPO or by the licensee (by way of the licence contract). In 2014, 37 PCT applications entered the national phase. In 2013 the figure was 36. The majority of these nationalised applications (76\%) were made by the University sector. 


\subsection{Patents granted}

The total number of patents granted in 2014 has dipped slightly to 50 from 59 in the previous year. However 2013 represented a 44\% increase over the previous year. The majority of these patents (88\%) were granted to inventions from the University sector. The rate of patent grant is not linear and depends on the complexity of prosecution within the relevant patent office and also where the application is being examined as some patent offices are more or less stringent in their approaches. The data as gathered therefore do not lend themselves to linking back to original filing. For the purposes of this analysis, patents granted in each territory in the year are counted even if they are related to the same original patent filing. The five year trend in the number of patents granted from 2010 to 2014 is shown in Figure 7.4.

\subsection{Reimbursement of patent costs}

Eight out of 21 RPOs said that they were able to achieve some reimbursement of patent costs from licensees in 2014. This ranged from $€ 3,500$ to over $€ 7$ million. One RPO was unable to track patent reimbursement ${ }^{19}$ and four $\mathrm{RPOs}^{20}$ were unable to provide information.

Figure 7.4:

Number of patents granted each year, 2010-2014

NUMBER OF PATENTS

70

$\begin{array}{r}59 \\ \hline\end{array}$

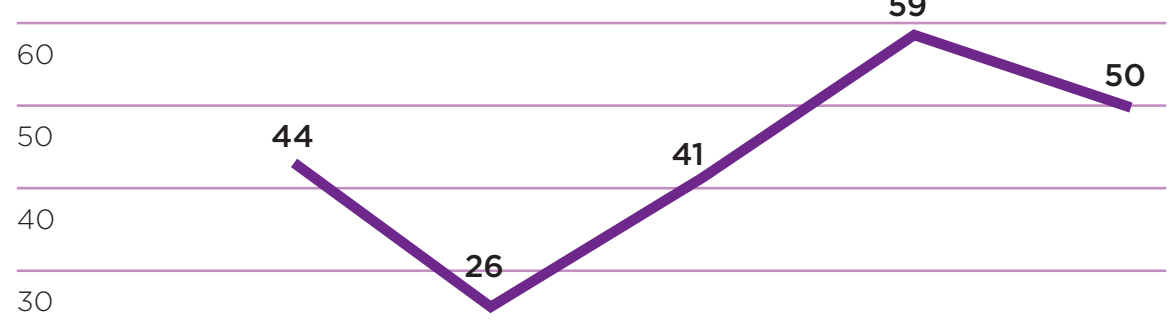

20

10

0
2012

2013

\footnotetext{
19 NCAD

20 Data not provided by IT Sligo, IT Tralee, NCI, NCAD
} 


\section{Licensing of rights}

Information was sought on all licences, options and assignments (LOAs) for all types of intellectual property generated in the institutions, including copyright, know-how, patents and trademarks. For this purpose, the terms were defined as follows:

- A licence is an agreement between an RPO and one or more third parties, whereby intellectual property rights are transferred for the purpose of commercialisation. The RPO retains ownership of the intellectual property but permits the licensee to exploit it in accordance with contractual terms and conditions.

- An option agreement is one in which the RPO grants a potential licensee or assignee a period of exclusivity during which it can decide whether it may wish to take a licence to the intellectual property and negotiate the terms of a licence agreement. The option period may include evaluation of the IP by the potential licensee (including assessing the technology). This is called an Option \& Evaluation agreement.

- An assignment is an agreement transferring ownership of intellectual property rights from the RPO to a third party.

\section{Figure 8.2:}

Total number of licences, options and assignments executed, $2010-2014$

NUMBER EXECUTED

\subsection{Licences, options and assignments (LOAs)}

There has been a sharp growth in the total number of licences, options and assignments executed by RPOs ${ }^{21}$ in 2014 from 139 to 168 i.e. an increase of $21 \%$. Licensing tends to be the dominant activity, at $58 \%$ of all LOAs signed (74\% in 2013). Options and assignments each accounted for $21 \%$ of LOAs signed. Despite the IP Protocol preferring that assignments are used only in certain cases, there has been a sharp increase in 2014. Nine assignments were signed in 2013 compared with 35 in 2014. The breakdown is shown in Figure 8.1.

Trends across licensing, options and assignments can be seen in Figure 8.2. A breakdown of licensing type by RPOs in Figure 8.3 shows that the University sector executed the majority of LOAs (75\%) in 2014 (68\% in 2013).

Figure 8.1

LOAs by type

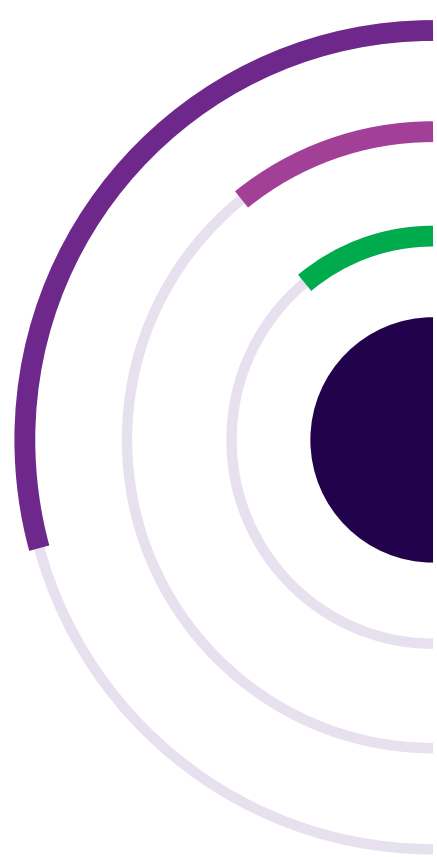

ABOVE

Licences

$97,58 \%$

- Options

$36,21 \%$

- Assignments $35,21 \%$

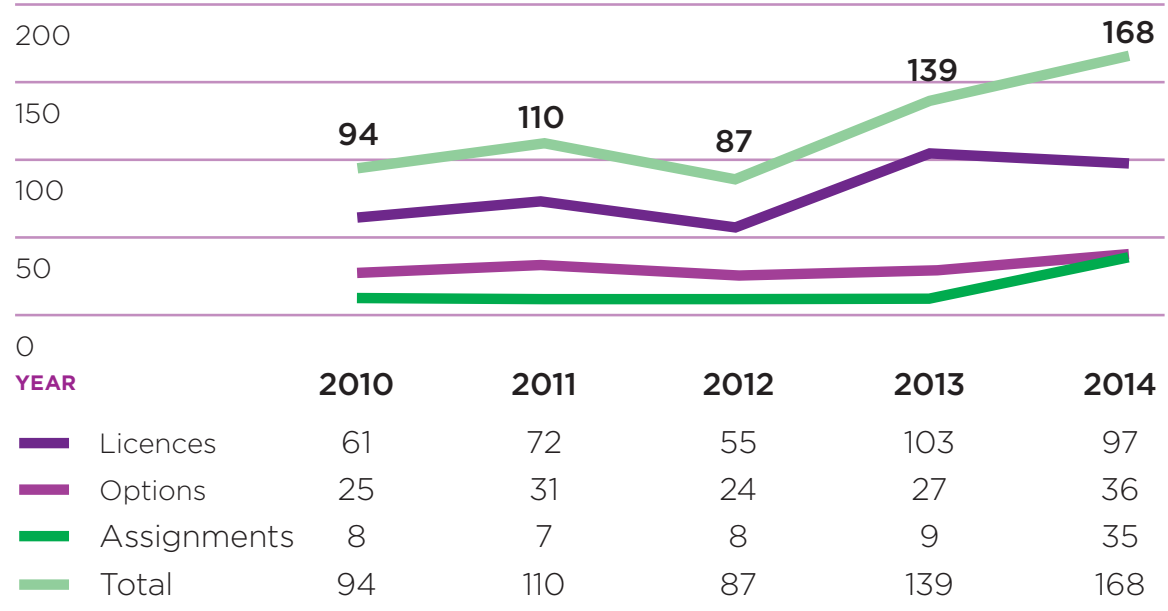


The total number of licence, option and assignment agreements active at the end of 2014 was 522 of which $79 \%$ were from the University sector. Figure 8.4 shows how the cumulative portfolio of active agreements steadily increased between 2009 and 2013 and then dipped slightly in 2014. As the number of new LOAs has increased, this dip may be due to the fact that some licences are terminating.
Figure 8.3:

Type and number of licences, options and assignments executed in 2014 by RPO

NUMBER EXECUTED

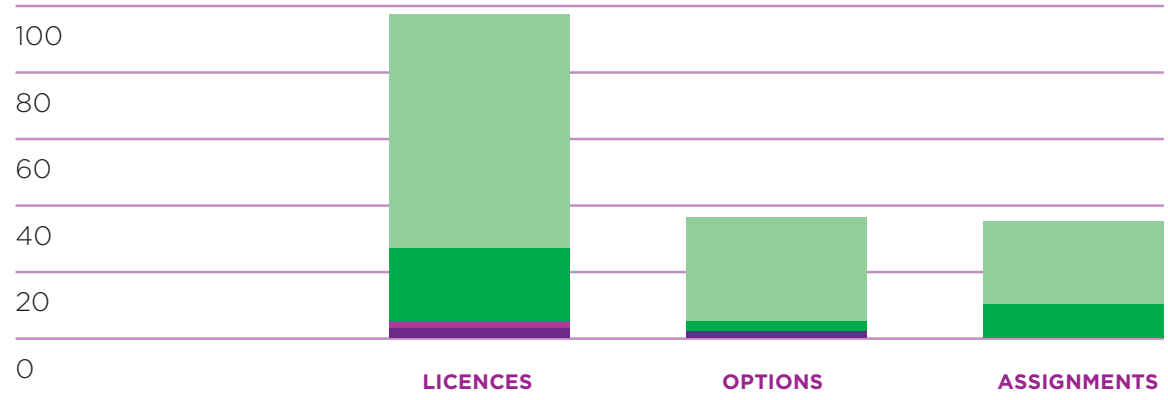

3

2

2

0

- Specialist Institute

22

0

0

70

10

25

Figure 8.4:

Total current licence and assignment portfolio, 2010 - 2014

NUMBER OF LOAS

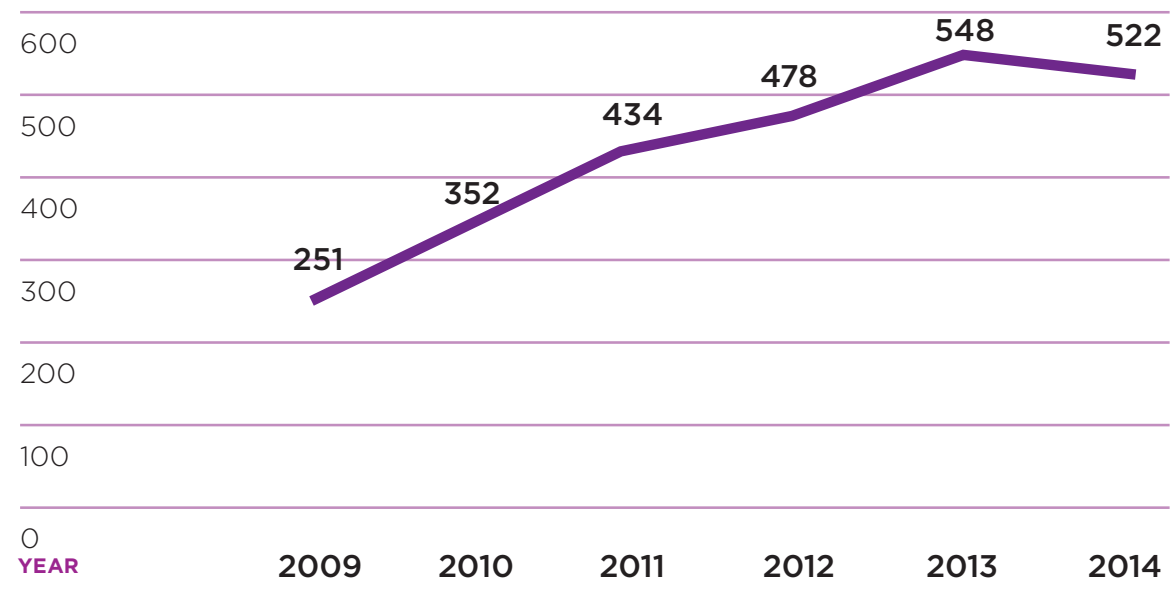


Figure 8.5:

Underpinning IP

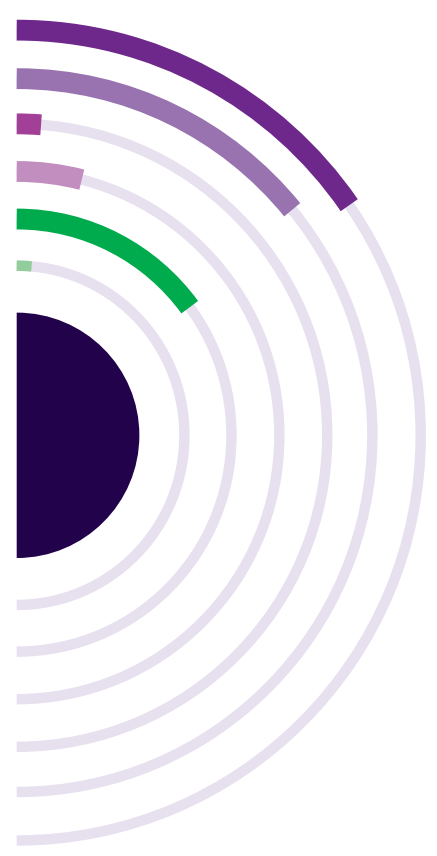

ABove

Patented IP

$58,30.5 \%$

Software

$53,28 \%$

Design rights
$5,2.5 \%$

Copyright

$13,7 \%$

Trade secret / know-how 56, 30\%

- Research materials

\subsection{Types of IP licensed}

Figure 8.5 shows the types of intellectual property that were the subject of licence agreements during 2014. More than one piece of IP may be licensed within one agreement e.g. software and know-how.

Figure 8.6:

Type of intellectual property in LOAs, 2010 - 2014

NUMBER OF LOAS

100

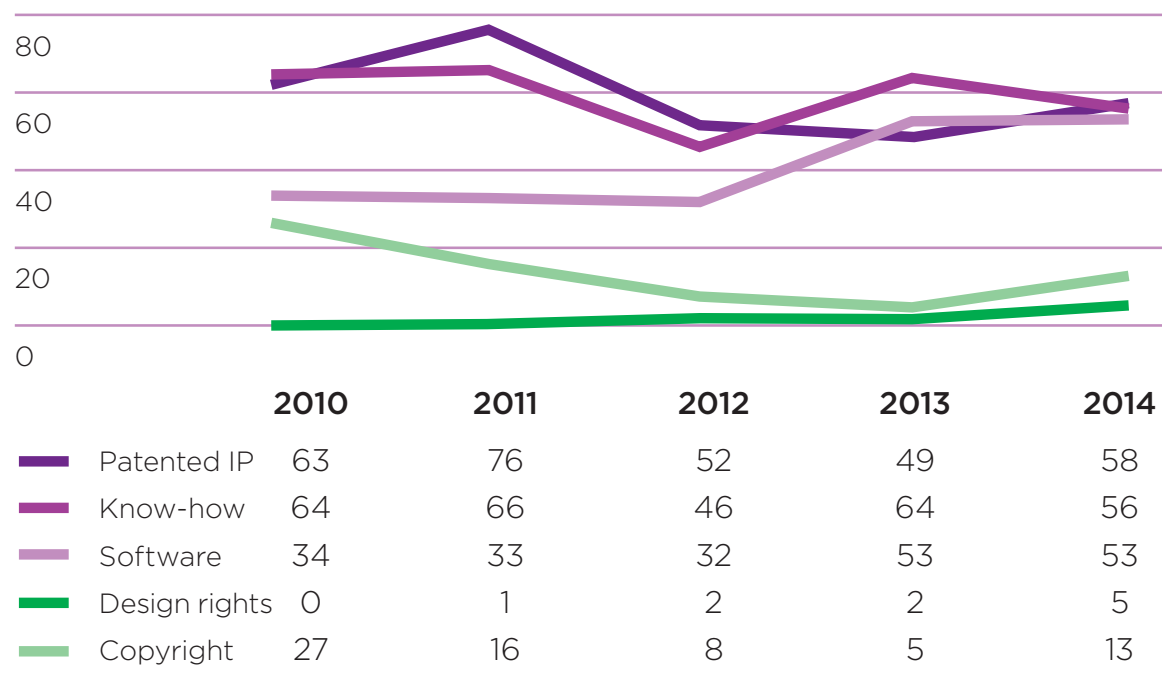

Trends over the past five years are shown in Figure 8.6 which indicates a steady rise in all types of IP licensed since the dip in 2012 with the greatest increase occurring in software licensing. 


\section{The Rosetta Foundation}

\section{Talking everyone's language}

The Rosetta Foundation, a University of Limerick (UL) spinout, has mobilised over 7,000 language volunteers worldwide on its innovative Translation Commons (www.trommons.org) platform. It currently delivers free translation services in 88 languages to 120 non-profit organisations as part of its mission to provide equal access to information and knowledge across the languages of the world.

The Rosetta Foundation is a spin-out of the Localisation Research Centre (LRC) at UL, and the Centre for Next Generation Localisation (CNGL), a research initiative supported by the Irish Government, Irish Universities, and industrial partners.

Research collaboration between four Irish universities and 10 industrial partners allowed the LRC to focus on the emerging field of community translation and localisation. A number of prototypes, leading to invention disclosures and licence agreements, were developed.

The Service-Oriented Localisation Architecture Solution (SOLAS), a flexible framework for localisation workflow automation was developed, based on open standards. SOLAS components were licensed to The Rosetta Foundation which deployed SOLAS as the Translation Commons,

'Trommons', facilitating the on- line collaboration of thousands of language volunteers.

In 2014 The Rosetta Foundation assisted the highest number of non-profit organisations since its launch, and it concluded two software licence agreements with UL to assist the further development of its service offering

Founder and CEO Reinhard Schäler had a vision for The Rosetta Foundation and the impact it could have on communities around the world. His ability to clearly communicate this vision and work closely with UL and the UL TTO has helped this vision to become a reality. He is confident that, "The excellent working relationship and close links between The Rosetta Foundation and the University of Limerick will continue into the future."

Added value from the university: intellectual property, licence, spin-out company creation 
Figure 8.7:

Licensee/assignee by type

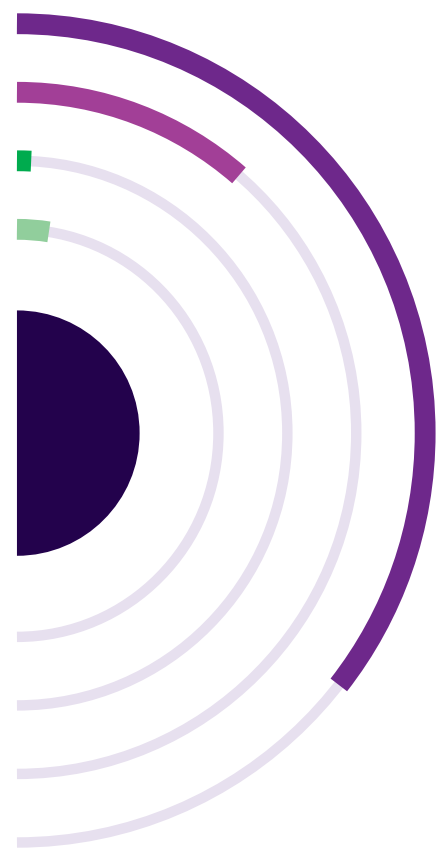

ABOVE

SME

$119,71 \%$

- MNC

$38,23 \%$

Non-commercial entity $2,1 \%$

Other

$9,5 \%$

\subsection{Licensees}

Figure 8.7 shows the types of organisations with which agreements were made in 2014. The majority of LOAs were transacted with SMEs (71\%). The percentage of LOAs signed with multinational companies (Irish-based and nonIrish based) was 23\%. Licensing to another RPO, for example in the case of joint inventorship or patent bundling, has been excluded from the analysis.
"Other" represents large Irish companies and High Potential StartUp companies (HPSUs).

The number of LOAs signed with companies has increased from 139 in 2013 to 159 in 2014, continuing the steady increase in LOAs executed from 94 in 2010. Looking at the extent of licensing to the Irish firm base, trends over the past five years show a slight decline in licensing to Irish companies.

\section{Figure 8.8:}

Location of licensee companies with whom LOAs executed

\section{PERCENTAGE OF LOAS EXECTUTED WITH INDUSTRY}

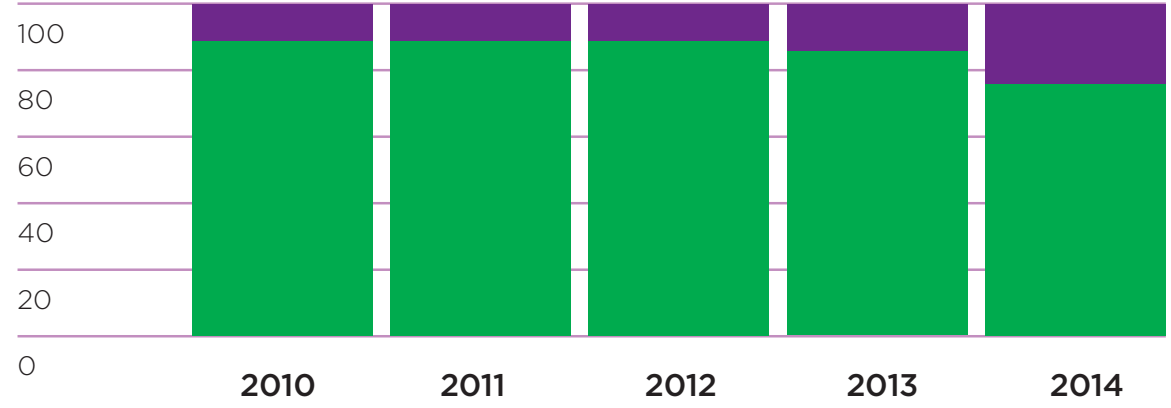

Industry with no activity in Ireland i.e. based overseas

Industry based in Ireland 


\subsection{Material transfer agreements (MTAs)}

A further type of agreement is a material transfer agreement, under which the institution transfers tangible research materials to another entity, and the recipient uses the materials for their own research purposes. The agreement specifies the rights of the provider and the recipient with respect to the materials and any derivatives. MTAs may be granted to or received from a commercial entity or another research organisation. Frequently, the transfer is out to a company by way of a licence agreement. 174 out-going MTAs were signed in 2014, with 116 issued to another RPO and 58 to a company.

The majority of MTAs in 2014 were reported by the University sector (80\%) with no loTs executing any formal materials transfer. Teagasc issued 32 MTAs with half going to companies.

\subsection{Products on the market}

30 previous licences from the Irish RPOs led to market launches of products or services in 2014. 21 of these (70\%) were from five Universities ${ }^{22}$ and six were from three IoTs $^{23}$. Three products were brought to market arising from research at NCAD. Neither of the two State research bodies provided data.

\section{A deeper dive into products launched in 2013}

A third party review was undertaken by IP Pragmatics, commissioned by $\mathrm{KTI}$, to examine new products and services that came onto the market in 2013 based on technology licensed from Irish RPOs. The available and validated data from the AKTS 2013 identified 26 such products. Once a technology has been transferred, the RPO may not be aware of the contribution of their IP to the products or services offered by licensees, particularly when the IP leads to improvements in existing products, rather than the development of a completely new product line. Therefore the number returned will be an underestimate of the contribution made by licences from RPOs to new launches.
The bulk of the licensees are in the ICT or Health and Med Tech sectors. The types of companies that have brought these licensed technologies to market range from small start-ups to multinational corporations. Nearly half of the licences are with RPO spin-out companies, in nearly all cases spun out from the same RPO.

Looking at the underpinning intellectual property, $61 \%$ of the underpinning licences were related to patent protected IP (29\%) and to software (32\%). The majority ( $85 \%)$ of products or services launched on the market in 2013 were by way of licences to Irish companies.

\footnotetext{
22 Data not provided by University of Limerick (UL) 


\section{Company creation}

There were a number of significant events in 2014 for existing RPO spin-outs. For example the UCD spin-out OxyMem established facilities in Athlone with the creation of 22 new jobs and began to fill its order book. WIT spin-out FeedHenry secured the second-highest valuation to date for a business developed from a spin-out from an Irish higher education institution when it was acquired for US\$82 million by Red Hat Inc. As part of the acquisition, US company Red Hat, established its first base in Ireland with 62 people now employed in Waterford and Dublin.

Information was sought on the number of spin-out and start-up companies established from RPOs in 2014. Sustainability of spin-out companies was also studied.

- A spin-out is a new incorporated company (created with the assistance of the TTO) whose business model and technology are based primarily on knowledge and/or intellectual property originating from the RPO and in which the RPO holds equity and/ or has executed a licence to the IP to the company.

- A start-up is a company formed by staff or students in the RPO whose business is not based on knowledge or intellectual property generated by the RPO and where there is no formal IP licence or equity share with the RPO.

- A spin-in is a company formed external to the RPO, which is not based on RPO IP, research or resources, and which does not involve RPO staff or students. In becoming a spin-in, the company becomes based in the RPO (for example, within an incubator) and/or provides equity to the RPO in exchange for access to business services from the TTO.

\subsection{New companies}

A total of 27 new companies were spun-out from 11 of the RPOs ${ }^{24}$ in 2014, down from 37 in 2013. Of these, 19 (70\%) were from the University sector, six (22\%) from the IOT sector and two were created out of NCAD (7\%). There were 14 staff start-ups recorded in the year, all in the IoT sector. A further 39 student start-ups were recorded across the university and IoT sectors. As they operate independently from the RPOs, start-ups will be underreported. Figure 9.1 shows the number of spin-outs and recorded start-ups established in the four

Figure 9.1:

Spin-outs and start-ups established, 2010 - 2014

NUMBER OF SPIN-OUTS AND START-UPS

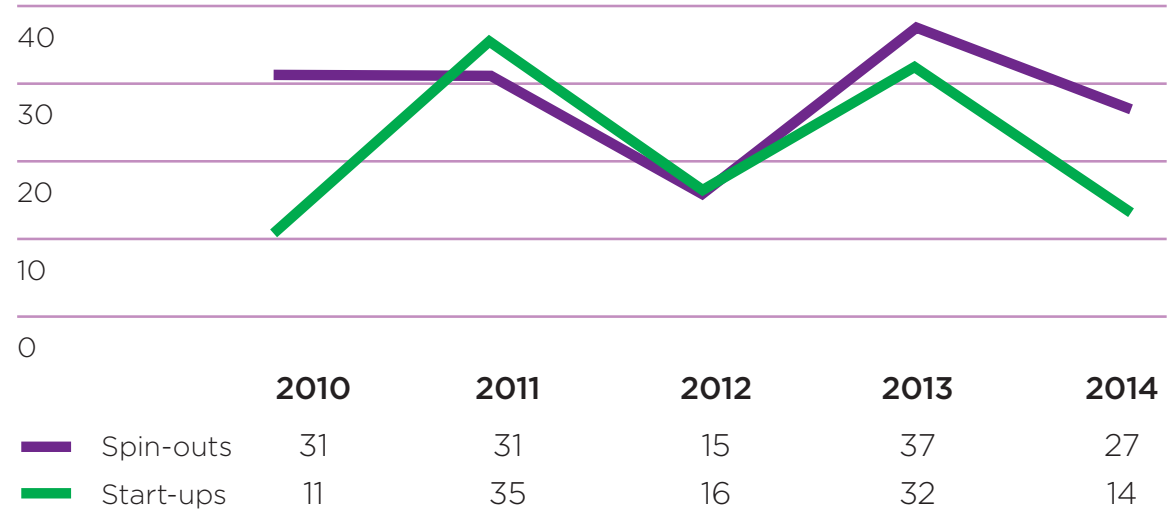




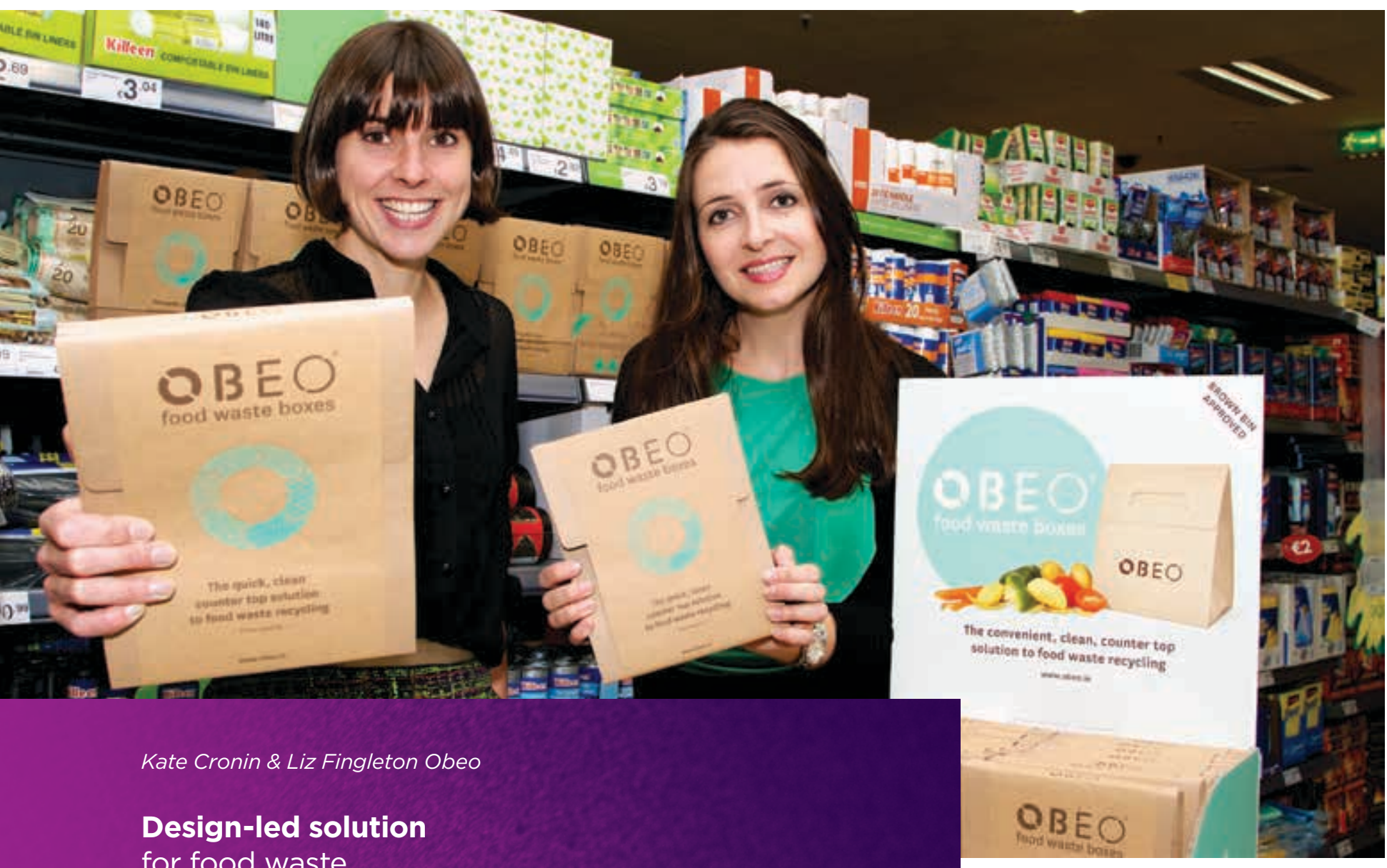

Obeo Ltd, a National College of Art and Design (NCAD) spin-out, launched the Obeo compostable food waste box in 2014, as a clever way to separate food waste without smells, mess or fuss.

Co-founded by Kate Cronin and Elizabeth Fingleton, Obeo received commercialisation funding from Enterprise Ireland to develop its product to a market ready stage, facilitated by Origin8, the design innovation and commercialisation gateway at NCAD.

Derek McGarry, head of design innovation and engagement, said, "We feel NCAD Origin8 is unique as it is primarily a design-led TTO This is enormously advantageous in helping our campus companies like Obeo develop their business offering by focusing specifically on customer need at the outset. Design thinking methods and principles are at the core of all the products we develop and start-ups we mentor."

Obeo also participated on the Bootcamp in NovaUCD and subsequently completed the 2013 UCD VentureLaunch Accelerator Programme, a threemonth accelerator programme delivered annually at NovaUCD.

With the Government introducing new household food waste regulations that require mandatory segregation of all household waste, an estimated 1.2 million brown bins will be rolledout to all serviced households in Ireland by the end of 2016, giving the Obeo compostable food waste box a readymade market.

The design and materials used in its manufacture are key to its convenience. Made from certified compostable materials the box breaks down naturally along with the food waste, without causing harm to the environment.

Co-founder Elizabeth Fingleton said, "We received mentoring from the head of design in the National College of Art \& Design during the prototyping stage of our project and the commercialisation advice and mentoring from NovaUCD proved invaluable to our spin-out company."

Added value from the university: business mentoring, spinout company creation 
Figure 9.2:

Active spin-outs at end of 2014 that are three or more years post-incorporation

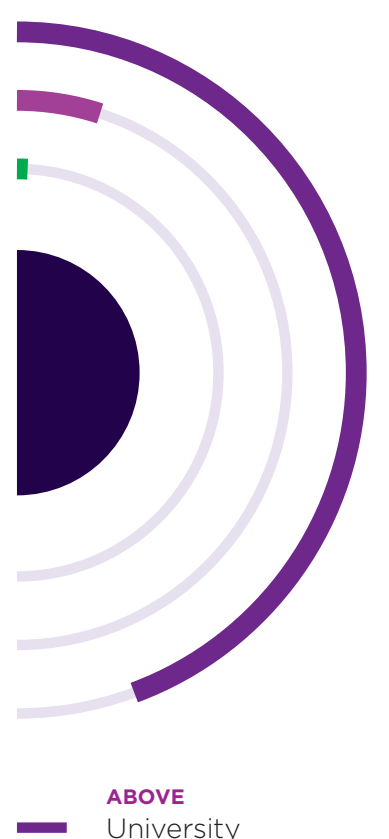

$86,89 \%$

Institute of Technology $10,10 \%$

Specialist Institute $1,1 \%$

\subsection{Active spin-out companies}

An active spin-out is defined as an RPO-created spin-out company that, as at the end of the reference year, has at least one paid employee and has raised equity and/or has booked sales revenue. It is an incorporated entity which at the time of formation was dependent on the exploitation of specific intellectual property rights of the RPO. The rights to the company can be linked to a specific researcher who was within the RPO at the time of company formation and who would be considered an academic founder. The RPO may or may not hold equity in the spin-out. This category excludes start-ups and spin-ins.

There were 97 active spin-outs at the end of 2014 that were at least three years post-incorporation. Of these, 86 were from the University sector (89\%) with 10 coming from the Institutes of Technology sector (10\%) and one from Teagasc. This is shown in Figure 9.2.

\section{A deeper dive into 2013's active spin-outs}

The data on active spin-out companies provided to the AKTS 2013 were explored further as a part of a review undertaken on behalf of KTI by IP Pragmatics. As a result of the review, the definition has been made clearer in the AKTS 2014. Additionally, data are now collected on those spin-outs that achieved a successful exit such as a trade sale so as to capture further impacts from RPO spin-outs.
The study showed that there were 78 spin-out companies reported by the RPOs as being active three or more years post formation. Of these companies, $64 \%$ are in the ICT or Health and Med Tech sectors. Of these active spinout companies, many have accessed more than one type of intellectual property to underpin their business. Patented technology constituted $45 \%$ of underpinning RPO licences and software a further $28 \%$.

All but one (99\%) of the active spin-outs are still located in Ireland, often remaining near their founding institution. Of these 78 active spinout companies, the study found that 23 (29\%) have established offices and/or appointed distribution agents in at least one overseas territory. Many of the others are trading abroad directly from their base in Ireland.

Looking back to formation date, 32 of the active spin-outs in 2013 had been formed in the 21 years prior to the introduction of the Enterprise Ireland TTSI programme in 2007. A further 46 currently active spin-outs had been formed in the four year period 2007-2010. Between them, RPO spin-out companies that remained active in 2013 provided employment for more than 660 people. Although investment data were not available for all the companies, IP Pragmatics determined that these spin-outs have raised in excess of $€ 203$ million in aggregate, based on the data available for 33 companies that have disclosed the amount of their investments. 


\subsection{Spin-in companies}

Many RPOs, frequently through their TTO, play a significant role in supporting early stage companies that are formed outside of the RPO with no initial connection to it. In becoming a spin-in the company becomes based in the RPO (for example, within an $\mathrm{HEl}$ incubator) and/or provides equity to the RPO in exchange for access to business services from the TTO. Recognising this, for the first time, the AKTS 2014 asked for information about spin-in companies. Figure $9.3^{25}$ shows the total number of spin-in companies (753) supported during 2014 and also the number of new entrants (253) in the HEl incubators.

Figure 9.3: Spin-in companies supported in 2014

NUMBER OF COMPANIES

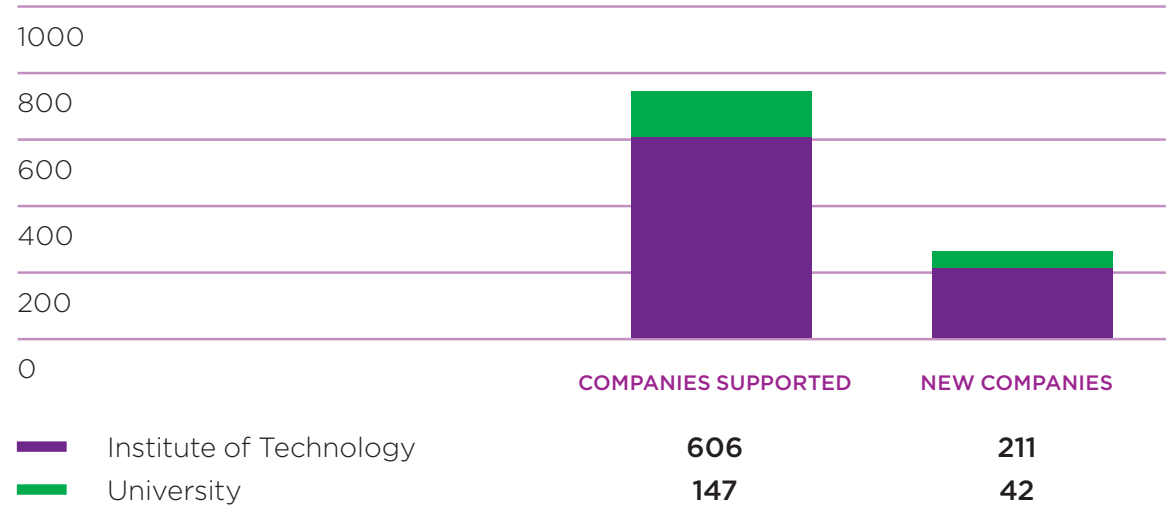

\subsection{Company incubation}

All Higher Education Institutes (HEls - universities and loTs) have an associated incubator facility in which early stage companies can develop. In addition to space for the company, services offered to the incubated company include advice on IP, networking events and access to professional services. According to the RPOs that returned data ${ }^{26}$ the total number of incubator clients at the end of 2014 was 755. The majority were based in IOT incubators (606) with 147 in University incubators and a further two companies supported in the NCAD incubator. The number of incubatees would be greater with the inclusion of data from the four missing loTs.

During 2014, a total of 343 new companies entered $\mathrm{HEl}$ incubators and 165 exited. The total number of companies supported at each incubator during 2014 ranged from nine to 123. Four HEl incubators hosted fewer than 20 companies, nine supported between 21 and 50 companies. At the remaining four $\mathrm{HEls}$, the range was from 75 to 123 companies supported in each of their incubators in 2014.

It is hard to be precise about the total number of FTE (full time equivalent) companies associated with the companies incubated in 2014. Only 16 RPOs that had incubated companies were able to return data and the number of incubated company FTEs in this sample set was 1676 .

\footnotetext{
25 Data not provided by IT Sligo, IT Carlow, IADT, $\mathrm{NCl}$, Marine Institute, Maynooth University

26 Data not provided by IT Sligo, IT Carlow, IADT, $\mathrm{NCl}$, Marine Institute
} 


\section{Back to the future} OptiWi-fi

The patent-protected congestion optimisation platform OptiWi$\mathrm{fi}$ is a graduate of the $2012 \mathrm{New}$ Frontiers programme at DIT Hothouse, the innovation and technology transfer centre at Dublin Institute of Technology (DIT). The company's core technology was developed in DIT's Communications Network Research Institute (CNRI) and licensed by DIT.

OptiWi-fi had a milestone year in 2014. It secured investment backing from communications giant Telefonica in October, and agreements with $\mathrm{O} 2$ Wifi to deploy its technology across O2's UK and Ireland networks.

OptiWi-fi improves wi-fi quality at congested hotspots. Providing operators with full visibility of bandwidth performance, it delivers autonomous, dynamic and real-time optimisation of their network, allowing them to identify and remedy issues before they affect user experience.

While OptiWi-fi is a new story, it has a long history. In 2001 research funding was granted by Enterprise Ireland to develop a wireless telephone link between two DIT buildings. Problems with bandwidth were identified and further funding was granted in 2002 under Enterprise Ireland's Applied Research Technology Programme, which led to a patent being filed in the US in 2004, with the assistance of DIT Hothouse.

On the strength of filing that patent, the researcher, Professor Mark Davis, and head of commercialisation at DIT, Tom Flanagan, visited the US for presentations to interested parties including Cisco and Microsoft, which responded enthusiastically but said the technology was ahead of its time.

With the arrival of the smartphone era and the ensuing exponential rise in mobile data transmission, the market eventually caught up with DIT's technology. In 2012, entrepreneur Mark Burke approached DIT on a speculative basis and, drawn to the potential of this technology, he provided DIT with funding. Further Enterprise Ireland funding was obtained to update the technology and add functionality.

Burke completed the New Frontiers programme at DIT Hothouse in 2012 and established OptiWi-fi together with Davis, a wi-fi patent inventor who manages the CNRI. "We are continuing to grow our workforce here in Ireland and build our business internationally, based on a foundation of research carried out and licensed at DIT," said Burke.

Added value from the Institute of Technology: intellectual property, licence, business mentoring, spin-out company creation

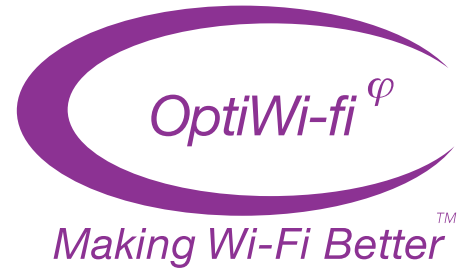




\title{
10 Revenue generation from licensing and spin-outs
}

\author{
Revenue generation from licensing IP or from the realisation \\ of spin-out equity may be considered a proxy for success. \\ Certainly it is a metric that is used in international analysis of \\ technology transfer performance. However, it is important to \\ put revenue generation in context.
}

Firstly, the objective of transferring IP into a company (existing or new) is to support business innovation and competitive advantage. This in turn should lead to the development of new services and products for the benefit of society and the economy. The relationship between business and entrepreneurs with RPOs is more sophisticated than simple rights acquisition; value is added through the other interactions that businesses have with the RPOs, such as access to expertise through research contracts and consultancy.
That said, revenue generation by the Irish RPO system tends to be a little lower than in other countries. This is due, in part, to the fact that the Irish TTO system is still relatively new (TTSI investment only commenced in 2007) and it takes many years for commercial prospects to yield revenue returns. For example, the IP that underpins the UCD spin-out OxyMem was originally filed in 2008 , but the company only raised its seed funding in 2013. The university will have to wait some time to realise its equity investment. Related to this, RPOs are frequently compelled to license IP too early, before real value has been developed. This is due to limited patent budgets which mean the RPO is often unable to take patent applications beyond PCT stage and so early rights to new IP are often granted to companies as part of research agreements. It is also due to the nature and appetite of the licensee. Irish SMEs and MNCs are often reluctant to share revenue with the RPO and frequently see access to IP arising from collaborations as a right, resulting in a high proportion of revenue-neutral assignments. 
Figure 10.1:

Licence revenue by RPO sector

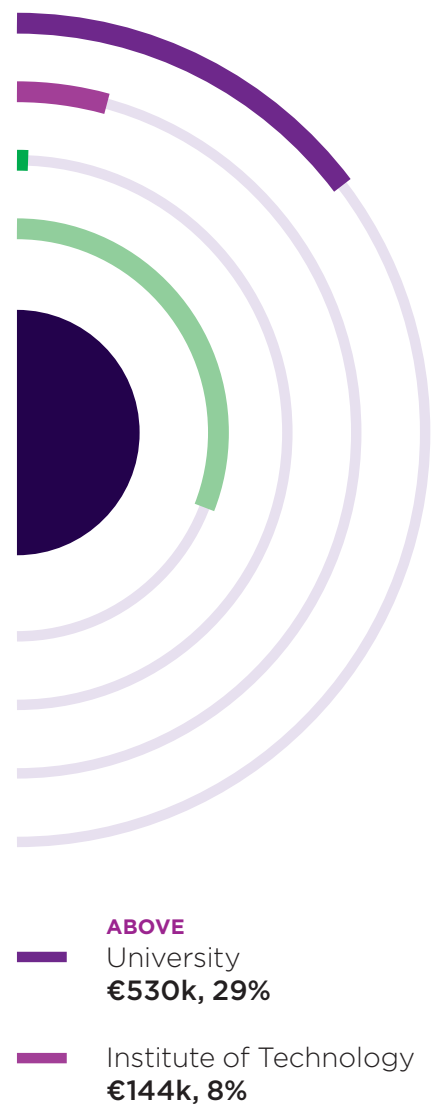

Specialist Institute $€ 14 \mathrm{k}, 1 \%$

State Research Body $€ 1,129 \mathrm{k}, 62 \%$

\subsection{Licence revenue}

The revenue from all types of know-how and IP (patents, copyright, designs, material transfer agreements, confidentiality agreements, plant breeder rights, etc.) before disbursement to the inventor or other parties was surveyed. Revenue includes licence issue fees, annual fees, royalties, option fees and milestones, termination and cash-in payments.

Only $20 \mathrm{RPOs}^{27}$ from the 23 RPOs reporting data to the AKTS this year were able to provide a figure for licence income. This is troubling given that revenue from licensing ought to be a trackable technology transfer outcome of interest to the RPO. One explanation given is that responsibility for recording licence income lies with finance teams, which are divorced from the TTO and may not appreciate the nuances of licensing income versus standard payments against invoices.

From the data provided, the aggregate revenue from licensing in 2014 was over $€ 1.8$ million (€1,816,184) up $20 \%$ on 2013 . The majority of licence income in 2014 (62\%) was related to the licensing of crops and plant varieties by Teagasc. All six universities that returned data reported revenue from licensing whilst only two out of 12 loTs generated licence income.

\subsection{Revenue from equity sale}

The realisation of equity is unpredictable, depending on external factors such as the maturity of the spin-out and market forces. Only two RPOs realised revenue from the sale of spin-out company equity in 2014. The total revenue was over $€ 1.4$ million, coming almost entirely from Waterford Institute of Technology. Only one RPO (UCD) saw a dividend return from equity holdings.

\footnotetext{
27 Data not provided by University of Limerick, IT Sligo, Marine Institute, IT Carlow, IADT, NC
} 


\section{Use of facilities and equipment}

Figure 11.1:

Number of contracts with companies for use of facilities and equipment by RPO type

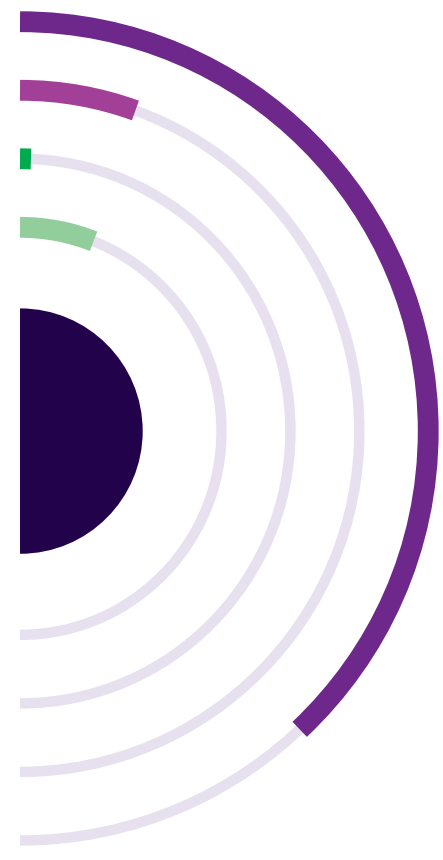

ABOVE

University

$660,76 \%$

Institute of Technology $104,12 \%$

Specialist Institute $5,0.6 \%$

State Research Body $100,11.4 \%$
The survey asked for information on the use of RPO facilities and equipment. Information is patchy because in the majority of cases the use of facilities and equipment by external organisations is managed at the local level, for example by a school or research department, and not tracked centrally. Only 17 of the 23 RPOs that responded to the survey were able to supply information and of these, five said that there were no contracts executed for the use of facilities or equipment.

Due to the incomplete data available, it is not possible to reflect the value that State investment in the RPO infrastructure is providing to industry.

A total of 869 contracts were recorded by 12 RPOs, up $94 \%$ on 2013. The majority of these are accounted for by two RPOs: Teagasc with 100 contracts and Trinity with 604. The range of contracts across the remaining 10 is 1-56 with only two of these RPOs having executed over 50 contracts. This is shown in Figure 11.1. The split by client is illustrated in Figure 11.2 which shows $51 \%$ of contracts were with MNCs, $43 \%$ with SMEs and $6 \%$ with noncommercial (non-academic) entities.

Revenue from access to facilities and equipment

Of the $18 \mathrm{RPO}^{28}$ that returned information on the use of facilities and equipment by business, 12 reported revenue generation. The gross revenue reported was over $€ 4.3$ million ( $€ 4,309,869$ ), more than double the figure for 2013. Half of this was generated by Teagasc.
Figure 11.2:

Number of contracts with companies for use of facilities and equipment by client type

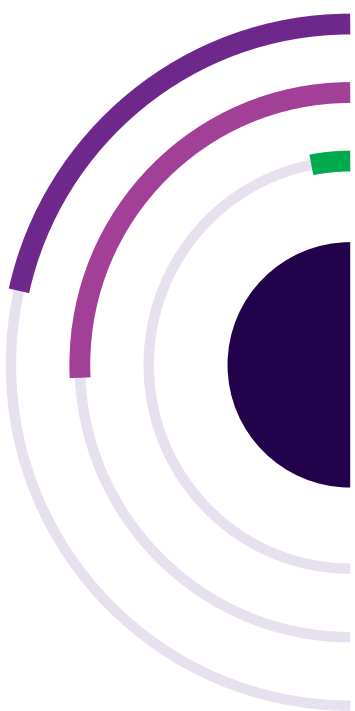

ABOVE

- SME

$373,43 \%$

- MNC

444, 51\%

Non-commercial entity $52,6 \%$ 


\section{Summary of commercialisation revenue}

Figure 12.1:

Revenue from

commercialisation

activities

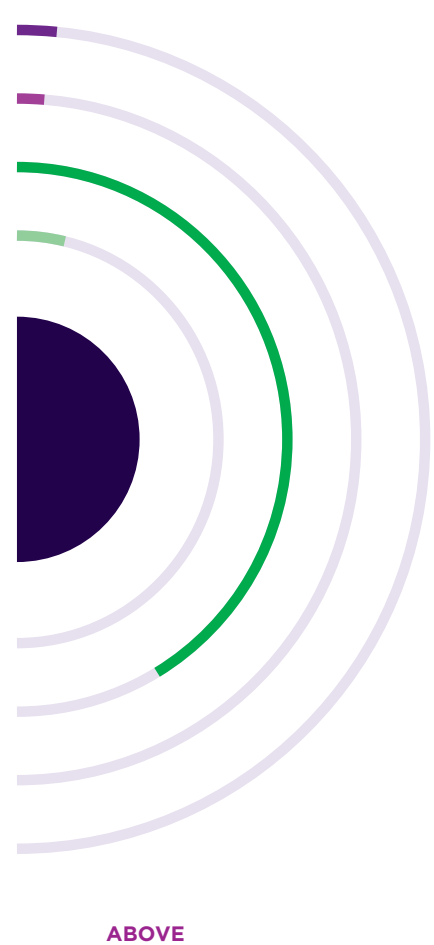

Licencing income

$€ 1.8 \mathrm{~m}, 3.1 \%$

Equity sale

$€ 1.4 \mathrm{~m}, 2.4 \%$

Collaborative \& contract research and consultancy $€ 50.2 \mathrm{~m}, 87 \%$

Use of facilities and equipment $€ 4.3 \mathrm{~m}, 7.5 \%$
The percentage of commercialisation revenue achieved in 2014 from licensing and equity sale was 5.5\% whilst revenue from engagement with industry (collaborative and contract research and consultancy) accounted for $87 \%$ of total revenue for the year. The data presented in Figure 12.1 exclude research income from State or other non-profit research funding sources, for example, research funding agencies and charities.

Table 12.1:

Revenue breakdown by source

\begin{tabular}{|l|r|r|}
\hline Revenue source & धM & \% of total \\
\hline Licensing income & 1.8 & 3.1 \\
\hline Equity sale \& dividends & 1.4 & 2.4 \\
\hline Collaborative \& contract research & 44.4 & 77 \\
\hline Consultancy & 5.8 & 10 \\
\hline Use of facilities and equipment & 4.3 & 7.5 \\
\hline TOTAL & 57.7 & 100 \\
\hline
\end{tabular}




\section{Knowledge transfer infrastructure}

Knowledge transfer is supported within RPOs through dedicated teams. These may range from a full technology transfer office (TTO) within a larger institution to an individual working part-time in a smaller institution. The functions are referred to differently. For example: "Technology Transfer"; "Industrial Liaison"; Knowledge Exchange"; "Innovation Office" etc. They are all (except for Letterkenny Institute of Technology which undertakes only incubation on business development) involved in supporting the transfer of technology, IP and knowledge between business and the RPO through related activities such as intellectual property management, licensing, partnering with industry, consultancy and the creation of new companies.

For the smaller loTs, this activity is supported by their TTSI programme consortium lead partner. Teagasc is currently prevented from creating spin-outs by its governance policy.

TTO staff are also increasingly involved in the often complex process of negotiating collaboration agreements with industry. In particular, the recent SFI centres have caused a large shift in resources from commercialisation activity to this research contracts support.
Additionally, staff in the majority of TTOs and ILOs are directly involved in providing support to the incubator facility. In some cases the incubator support staff are part of the ILO.

TTO and ILO staff also play a role in supporting staff and student enterprise, delivering entrepreneurial training and supporting business plan competitions.
Below: Richard Stokes, Director of Innovation, Invent DCU; Tom

Flanagan, Director, DIT Hothouse; Dr. Tim Roche, Director, Technology Transfer, UCC; Brendan Cremen, Director, Enterprise \&

Commercialisation, UCD and Dr. Alison Campbell, Director, KTI at the Knowledge Transfer Community Forum 2014.

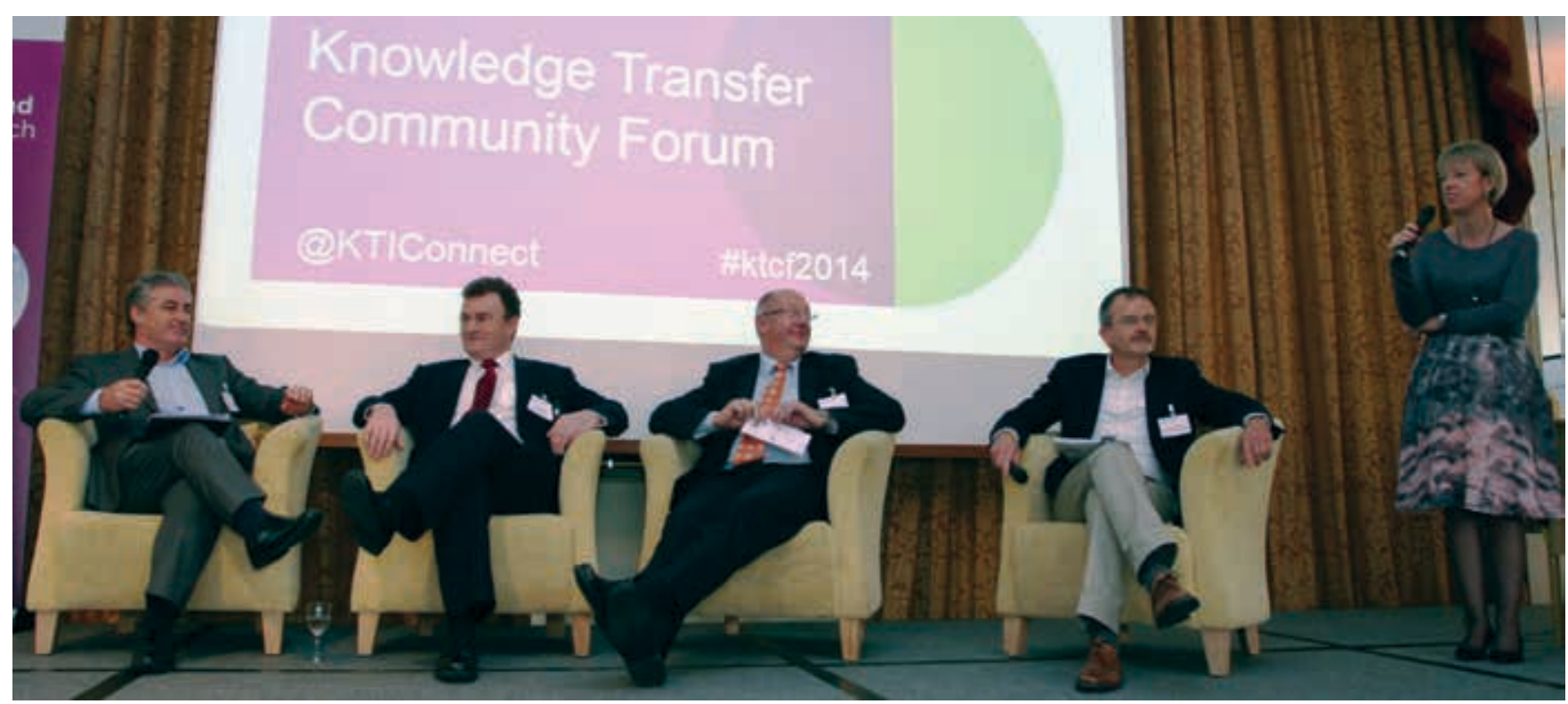




\section{Appendix 1}

\section{Summary data by RPO}

\section{Selected data relating to the returns made by the 23 RPOs (listed at} $A$, right) are presented. Where an RPO was unable to return data, the entry is greyed out.

The data cannot be viewed as league tables of performance. Activity and outcomes depend on a complex range of factors which include the RPO mission, activity and research base. For example, one RPO may be more focused on working with many local companies on small-scale projects whilst another larger RPO may have a greater breadth and depth of research in an area that lends itself to a more national or international engagement and creation of IP. Other factors include the resourcing to support KT activity and how long a TTO/ILO has been in existence. It also needs to be recognised that some of the information requested had to be obtained from different departments within the RPO and not all data may be captured with the same level of detail or provided with the same rigour. This should improve as the AKTS becomes more established as the annual process for collecting national KT data.

\section{A: Year of foundation of TTO/ILO}

\begin{tabular}{|l|r|}
\hline University & \\
\hline Dublin City University & 1988 \\
\hline Maynooth University & 2007 \\
\hline NUI Galway & 1982 \\
\hline Trinity College Dublin & 1987 \\
\hline University College Dublin & 2005 \\
\hline University College Cork & 1987 \\
\hline University of Limerick & 2005 \\
\hline Specialist and State & \\
\hline Research Organisations & 2007 \\
\hline Marine Institute & 2013 \\
\hline National College of Art and Design & 2011 \\
\hline Royal College of Surgeons in Ireland & 2009 \\
\hline Teagasc & 2008 \\
\hline Institutes of Technology & 2008 \\
\hline
\end{tabular}


B1: Research expenditure, research agreements and consultancy 2014: University, Specialist and State research organisations ${ }^{29}$
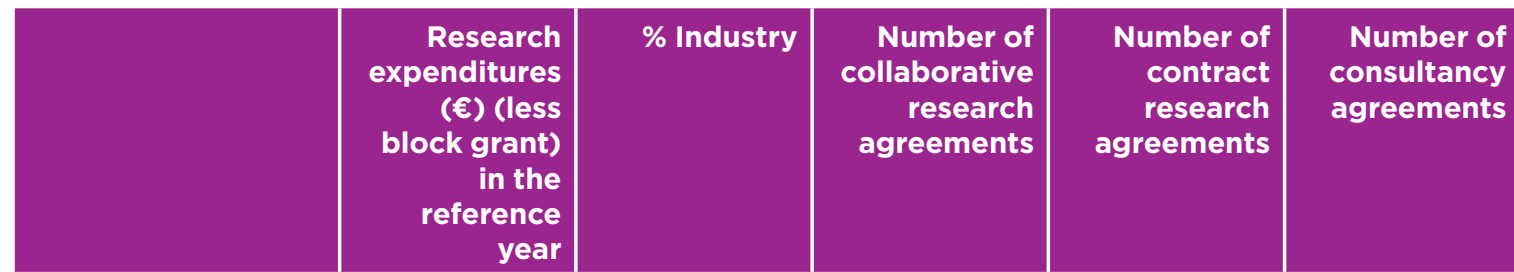

Total number collaboration, contract and consultancy agreements

\section{University}

Dublin City

University

$€ 35,000,000$

Maynooth University

$€ 20,897,000$

12.00

82

6

6

1

8.50

109

o

12

121

NUI Galway

$€ 52,171,636$

5.65

28

26

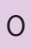

Trinity College

$€ 91,185,609$

2.70

44

30

10

\section{Dublin}

University College
Dublin
University College
Cork
University of
Limerick

$€ 80,570,000$

$€ 83,900,000$

3.10

77

\section{8}

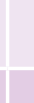

7.00

100

195

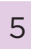

$€ 25,830,000$

8.60

Limerick

\section{Specialist and State research organisations}

\begin{tabular}{|l|r|r|r|r|r|r|}
\hline Marine Institute & $€ 3,400,000$ & 1 & 0 \\
\hline $\begin{array}{l}\text { National College of } \\
\text { Art and Design }\end{array}$ & $€ 181,169$ & 45.00 & 2 & 20 & 6 \\
\hline $\begin{array}{l}\text { Royal College of } \\
\text { Surgeons in Ireland }\end{array}$ & $€ 16,028,079$ & 6.00 & 4 & 1 & 6 \\
\hline Teagasc & $€ 40,269,000$ & 10.00 & 9 & 6 & 250 \\
\hline
\end{tabular}




\section{B2: Research expenditure, research agreements and consultancy 2014: Institutes of Technology30}

\begin{tabular}{|c|c|c|c|c|c|c|}
\hline & $\begin{array}{r}\text { Research } \\
\text { expenditures } \\
(€) \text { (less } \\
\text { block grant) } \\
\text { in the } \\
\text { reference } \\
\text { year }\end{array}$ & $\%$ Industry & $\begin{array}{r}\text { Number of } \\
\text { collaborative } \\
\text { research } \\
\text { agreements }\end{array}$ & $\begin{array}{r}\text { Number of } \\
\text { contract } \\
\text { research } \\
\text { agreements }\end{array}$ & $\begin{array}{l}\text { Number of } \\
\text { consultancy } \\
\text { agreements }\end{array}$ & $\begin{array}{l}\text { Total number } \\
\text { collaboration, } \\
\text { contract and } \\
\text { consultancy } \\
\text { agreements }\end{array}$ \\
\hline $\begin{array}{l}\text { Athlone Institute of } \\
\text { Technology }\end{array}$ & $€ 3,119,000$ & 10.00 & 11 & 204 & 5 & 220 \\
\hline $\begin{array}{l}\text { Cork Institute of } \\
\text { Technology }\end{array}$ & $€ 17,173,715$ & 10.74 & 23 & 67 & 76 & 166 \\
\hline $\begin{array}{l}\text { Dublin Institute of } \\
\text { Technology }\end{array}$ & $€ 10,211,519$ & 2.10 & 11 & 9 & 17 & 37 \\
\hline $\begin{array}{l}\text { Dundalk Institute of } \\
\text { Technology }\end{array}$ & $€ 6,230,000$ & 2.00 & 35 & 29 & 0 & 64 \\
\hline $\begin{array}{l}\text { Galway-Mayo } \\
\text { Institute of } \\
\text { Technology }\end{array}$ & $€ 619,556$ & 32.00 & 2 & 35 & 0 & 37 \\
\hline $\begin{array}{l}\text { Institute of } \\
\text { Technology Sligo }\end{array}$ & $€ 1,780,000$ & 12.00 & 35 & 0 & 0 & 35 \\
\hline $\begin{array}{l}\text { Institute of } \\
\text { Technology Tallaght }\end{array}$ & $€ 2,095,885$ & 10.38 & 42 & 39 & 0 & 81 \\
\hline $\begin{array}{l}\text { Institute of } \\
\text { Technology Tralee }\end{array}$ & $€ 1,490,697$ & 5.00 & 14 & 2 & 0 & 16 \\
\hline $\begin{array}{l}\text { Institute of } \\
\text { Technology } \\
\text { Blanchardstown }\end{array}$ & $€ 615,563$ & 20.47 & 7 & 0 & 3 & 10 \\
\hline $\begin{array}{l}\text { Limerick Institute of } \\
\text { Technology }\end{array}$ & $€ 2,223,953$ & 0.14 & 5 & 4 & 0 & 9 \\
\hline $\begin{array}{l}\text { Letterkenny Institute } \\
\text { of Technology }\end{array}$ & $€ 921,000$ & 0 & 0 & 13 & 1 & 14 \\
\hline $\begin{array}{l}\text { Waterford Institute } \\
\text { of Technology }\end{array}$ & $€ 17,517,476$ & 2.00 & 6 & 459 & 0 & 465 \\
\hline
\end{tabular}

30 Data supplied by RPO 


\section{C1: IP and IP transactions 2014: University, Specialist and State research organisations}

\begin{tabular}{|c|c|c|c|c|c|c|c|}
\hline & $\begin{array}{r}\text { Total } \\
\text { number of } \\
\text { invention/ } \\
\text { software } \\
\text { disclosures } \\
\text { in year (sole } \\
\text { and joint) }\end{array}$ & $\begin{array}{r}\text { Total } \\
\text { number } \\
\text { of priority } \\
\text { patent } \\
\text { applications } \\
\text { during the } \\
\text { year }\end{array}$ & $\begin{array}{r}\text { Previously } \\
\text { flled priority } \\
\text { patent } \\
\text { applications } \\
\text { progressed } \\
\text { to PCT in } \\
\text { year \% }\end{array}$ & $\begin{array}{r}\text { Total } \\
\text { number } \\
\text { of patents } \\
\text { granted in } \\
\text { year }\end{array}$ & $\begin{array}{r}\text { Total } \\
\text { number } \\
\text { of patent } \\
\text { families } \\
\text { owned by } \\
\text { the RPO at } \\
\text { year end }\end{array}$ & $\begin{array}{r}\text { Total } \\
\text { number of } \\
\text { licences, } \\
\text { options and } \\
\text { assignments } \\
\text { executed } \\
\text { (LOAS) }\end{array}$ & $\begin{array}{r}\text { Market } \\
\text { launches in } \\
\text { year based } \\
\text { on RPO } \\
\text { licence }\end{array}$ \\
\hline $\begin{array}{l}\text { Dublin City } \\
\text { University }\end{array}$ & 33 & 13 & 55 & 12 & 86 & 25 & 2 \\
\hline $\begin{array}{l}\text { Maynooth } \\
\text { University }\end{array}$ & 14 & 3 & 0 & 1 & 20 & 6 & 2 \\
\hline NUI Galway & 40 & 6 & 12.9 & 3 & 62 & 15 & 0 \\
\hline $\begin{array}{l}\text { Trinity College } \\
\text { Dublin }\end{array}$ & 56 & 21 & 28 & 6 & 93 & 26 & 12 \\
\hline $\begin{array}{l}\text { University } \\
\text { College Dublin }\end{array}$ & 66 & 23 & 57 & 6 & 86 & 24 & 3 \\
\hline $\begin{array}{l}\text { University } \\
\text { College Cork }\end{array}$ & 68 & 18 & 54 & 9 & 110 & 21 & 2 \\
\hline $\begin{array}{l}\text { University of } \\
\text { Limerick }\end{array}$ & 29 & 6 & 27 & 7 & 19 & 9 & \\
\hline $\begin{array}{l}\text { Marine } \\
\text { Institute }\end{array}$ & 0 & 0 & 0 & 0 & 0 & 0 & \\
\hline $\begin{array}{l}\text { National } \\
\text { College of Art } \\
\text { and Design }\end{array}$ & 2 & 3 & 0 & 0 & 0 & 2 & 3 \\
\hline $\begin{array}{l}\text { Royal College } \\
\text { of Surgeons in } \\
\text { Ireland }\end{array}$ & 6 & 4 & 100 & 3 & 32 & 0 & 0 \\
\hline Teagasc & 15 & 3 & 66 & 1 & 19 & 5 & \\
\hline
\end{tabular}




\section{C2: IP and IP transactions 2014: Institutes of Technology}

\begin{tabular}{|c|c|c|c|c|c|c|c|}
\hline & $\begin{array}{r}\text { Total } \\
\text { number of } \\
\text { invention/ } \\
\text { software } \\
\text { disclosures } \\
\text { in year (sole } \\
\text { and joint) }\end{array}$ & $\begin{array}{r}\text { Total } \\
\text { number } \\
\text { of priority } \\
\text { patent } \\
\text { applications } \\
\text { during the } \\
\text { year }\end{array}$ & $\begin{array}{r}\text { Previously } \\
\text { filed priority } \\
\text { patent } \\
\text { applications } \\
\text { progressed } \\
\text { to PCT in } \\
\text { year \% }\end{array}$ & $\begin{array}{r}\text { Total } \\
\text { number } \\
\text { of patents } \\
\text { granted in } \\
\text { year }\end{array}$ & $\begin{array}{r}\text { Total } \\
\text { number } \\
\text { of patent } \\
\text { families } \\
\text { owned by } \\
\text { the RPO at } \\
\text { year end }\end{array}$ & $\begin{array}{r}\text { Total } \\
\text { number of } \\
\text { licences, } \\
\text { options and } \\
\text { assignments } \\
\text { executed } \\
\text { (LOAs) }\end{array}$ & $\begin{array}{r}\text { Market } \\
\text { launches in } \\
\text { year based } \\
\text { on RPO } \\
\text { licence }\end{array}$ \\
\hline $\begin{array}{l}\text { Athlone } \\
\text { Institute of } \\
\text { Technology }\end{array}$ & 5 & 2 & 0 & 0 & 0 & 2 & 0 \\
\hline $\begin{array}{l}\text { Cork } \\
\text { Institute of } \\
\text { Technology }\end{array}$ & 21 & 2 & 33 & 1 & 10 & 7 & 1 \\
\hline $\begin{array}{l}\text { Dublin } \\
\text { Institute of } \\
\text { Technology }\end{array}$ & 32 & 8 & 50 & 1 & 36 & 16 & 4 \\
\hline $\begin{array}{l}\text { Dundalk } \\
\text { Institute of } \\
\text { Technology }\end{array}$ & 1 & 0 & 0 & 0 & 2 & 0 & 0 \\
\hline $\begin{array}{l}\text { Galway-Mayo } \\
\text { Institute of } \\
\text { Technology }\end{array}$ & 2 & 0 & 0 & 0 & 0 & 0 & 0 \\
\hline $\begin{array}{l}\text { Institute of } \\
\text { Technology } \\
\text { Sligo }\end{array}$ & 2 & & & & & & \\
\hline $\begin{array}{l}\text { Institute of } \\
\text { Technology } \\
\text { Tallaght }\end{array}$ & 4 & 0 & 66 & 0 & 0 & 2 & 0 \\
\hline $\begin{array}{l}\text { Institute of } \\
\text { Technology } \\
\text { Tralee }\end{array}$ & 2 & 0 & 0 & 0 & 0 & 0 & 0 \\
\hline $\begin{array}{l}\text { Institute of } \\
\text { Technology }\end{array}$ & 2 & 2 & & 0 & 2 & 1 & 1 \\
\hline $\begin{array}{l}\text { Limerick } \\
\text { Institute of } \\
\text { Technology }\end{array}$ & 5 & 0 & 0 & 0 & 0 & 1 & 0 \\
\hline $\begin{array}{l}\text { Letterkenny } \\
\text { Institute of } \\
\text { Technology }\end{array}$ & 1 & 0 & 0 & 0 & 0 & 1 & 0 \\
\hline $\begin{array}{l}\text { Waterford } \\
\text { Institute of } \\
\text { Technology }\end{array}$ & 17 & 3 & 12.5 & 0 & 8 & 5 & 0 \\
\hline
\end{tabular}


D1: Spin-out companies, incubation and use of facilities 2014: University, Specialist and State research organisations

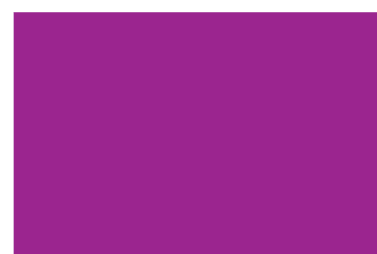

Dublin City University

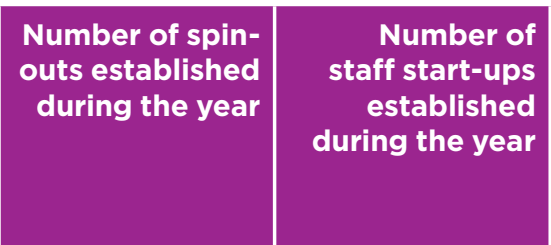

3

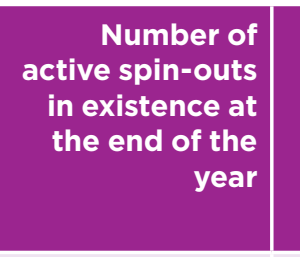

0

5

Maynooth University 2

NUI Galway

Trinity College Dublin

University College

Dublin

University College Cork
University of Limerick
Marine Institute
National College of Art
and Design
Royal College of
Surgeons in Ireland

Teagasc

\section{2}

5
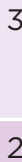

2

2

0

0

2

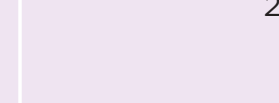

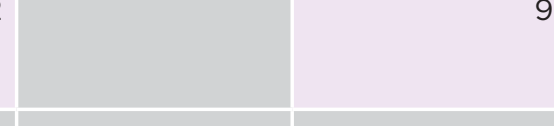

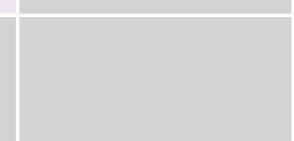

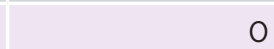

(n)

o

O
Number of companies supported within the incubator year
Number of contracts with companies for use of facilities and equipment at the RPO
6

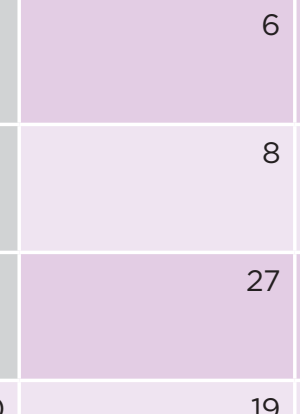

19

12

9

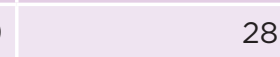

28

O
8

27

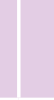

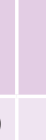

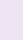

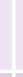

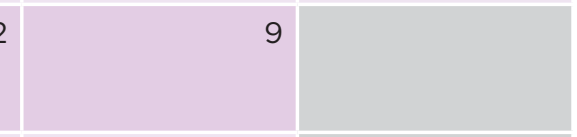

34

11

37

54
O

2

5

28

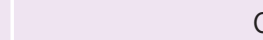

O

1 
D2: Spin-out companies, incubation and use of facilities 2014: Institutes of Technology

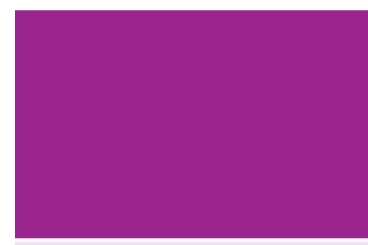

Athlone Institute of Technology

\section{Cork Institute of}

Technology

Dublin Institute of

Technology

Dundalk Institute of

Technology

Galway-Mayo Institute of Technology

Institute of Technology Sligo

Institute of Technology Tallaght

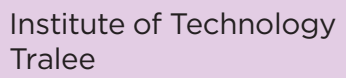

Institute of Technology Blanchardstown

Limerick Institute of

Technology

Letterkenny Institute of Technology

Waterford Institute of Technology
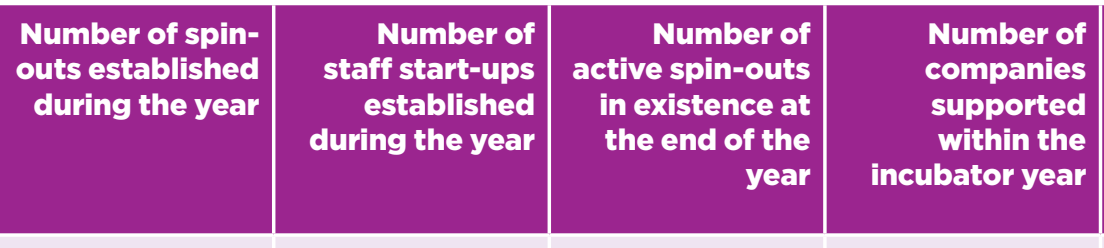

\section{Number of contracts with companies for use of facilities and equipment at the RPO}

\section{4}

O

0

123

4

0

7

89

5

O

0

0

o

0

O

16

O

25

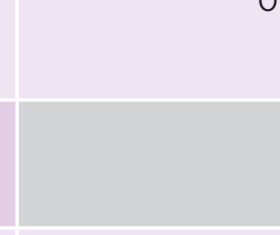

o

0

o

75

56

0

O

o

28

0

0

0

48

0

O

0

O

14

0

12

31

0 


\section{Appendix 2 \\ List of Research Performing Organisations (RPOs)}

Those not returning data for 2014 in green

\begin{tabular}{|c|c|}
\hline Reporting Sector & Institution \\
\hline University & $\begin{array}{l}\text { Dublin City University } \\
\text { Maynooth University } \\
\text { National University of Ireland Galway } \\
\text { Trinity College Dublin } \\
\text { University College Cork } \\
\text { University College Dublin } \\
\text { University of Limerick - partial return only }\end{array}$ \\
\hline Institute of Technology & $\begin{array}{l}\text { Athlone Institute of Technology } \\
\text { Cork Institute of Technology } \\
\text { Dublin Institute of Technology } \\
\text { Dun Laoghaire Institute of Art, Design \& Technology } \\
\text { Dundalk Institute of Technology } \\
\text { Galway-Mayo Institute of Technology } \\
\text { Institute of Technology Blanchardstown } \\
\text { Institute of Technology Carlow } \\
\text { Institute of Technology Sligo - partial return only } \\
\text { Institute of Technology Tallaght } \\
\text { Institute of Technology Tralee } \\
\text { Letterkenny Institute of Technology } \\
\text { Limerick Institute of Technology } \\
\text { Waterford Institute of Technology }\end{array}$ \\
\hline Specialist Institute & $\begin{array}{l}\text { National College of Art and Design } \\
\text { National College of Ireland } \\
\text { Royal College of Surgeons in Ireland }\end{array}$ \\
\hline State Body Sector & $\begin{array}{l}\text { Marine Institute - partial return only } \\
\text { Teagasc }\end{array}$ \\
\hline
\end{tabular}




\section{Appendix 3 Glossary}

\section{Active spin-out}

An RPO-created spin-out company that, as at the end of the reference year, has at least one paid employee and has raised equity and/or it has booked sales revenue. It is an incorporated entity which at the time of formation was dependent on the exploitation of specific intellectual property rights of the $\mathrm{RPO}$. The rights to the company can be linked to a specific researcher who was within the RPO at the time of company formation and who would be considered an academic founder. The RPO may or may not hold equity in the spin-out. (Exclude start-ups and spin-ins. To avoid double counting, do not include as an RPO spin-out those companies to whom your RPO licensed IP but where the academic founder(s) were based at another RPO).

\section{Assignment}

Contract transferring ownership of right in IP to a third party.

\section{Collaborative research agreement}

Contractual arrangement whereby both the RPO and company (or noncommercial entity) jointly develop the work plan. Funding may be solely from the third party but is likely to involve some level of cofunding from government sources. (Excludes contract research, consultancy and research grants).

\section{Consultancy agreement}

Contractual arrangement in which the RPO provides expert advice without performing new research. (Excludes collaborative research, contract research, and research grants).

\section{Contract research agreement}

Contract where the company specifies the work to be undertaken by the RPO and pays all the costs of the work programme. This includes agreements that may involve a "work order" or may be considered as "contract services". (Excludes collaborative research, consultancy and research grants).

\section{Equity}

Shareholding in a legal entity.

\section{FTE}

Full Time Equivalents - People working part-time are only included for the fraction that they are employed.

Incubator

A dedicated facility on the RPO campus in which early stage companies are housed and supported (pre- and post-formation). The facility may offer desk space, laboratory space or a mix of both.

\section{Invention disclosure}

The invention disclosure is the first step in a process that could potentially lead to commercialisation of technology. The researcher and TTO/ILO will complete an Invention Disclosure Form (IDF) which is a written, dated record of an invention. It contains basic information which helps to evaluate, subsequently protect and potentially commercialise the intellectual property associated with an invention. An invention disclosure becomes a Qualified Invention Disclosure when it has been evaluated by the TTO/ILO staff or other technology experts to assess their commercial application and then accepted into the TTO/ ILO system for further progression.

\section{ILO}

Industry Liaison Office - the team responsible for managing $\mathrm{KT}$ services, including intellectual property management, licensing, partnering with industry and the creation of new companies.

\section{Joint qualified invention/} software disclosure

Simultaneous reporting of the same invention to more than one RPO of tangible inventions/software that has been created jointly by more than one RPO. The disclosures are reported to each TTO/ILO and are then evaluated by the TTO/ILO staff or other technology experts to assess their commercial application and then accepted into the TTO/ ILO system for further progression.

\section{$\mathrm{KT}$}

Knowledge transfer - the sharing of expertise, capability, technology and intellectual property between the research base and industry or the public sector with the aim of developing new or improved products, processes and services that deliver societal and economic benefit.

\section{Licence}

A contract under which IP rights are transferred from one party to another for the purpose of commercialisation.

\section{MNC}

A multinational corporation that has its facilities and other assets in at least one country other than its home country. Such companies have offices and/or factories in different countries and usually have a centralised head office where they coordinate global management. 
MNC Irish

$\mathrm{HQ}$ based in Ireland.

Non-commercial entity

Public sector organisation or charity.

Non-commercial entity (Irish)

$H Q$ based in Ireland.

\section{Option}

A contract under which the RPO grants a potential licensee a period of exclusivity during which it can decide whether it may wish to take a licence to the intellectual property and negotiate the terms of a licence agreement. The option period may include evaluation of the IP by the potential licensee (including assessing the technology). This is may be called an Option \& Evaluation agreement.

\section{PCT}

Patent Cooperation Treaty - the Treaty makes it possible to seek patent protection for an invention simultaneously in each of a large number of countries by filing an "international" patent application.

\section{Priority filing}

The first filing of a patent application which will establish a priority date from which all national patents will derive. Depending on patent strategy the priority filing may be done as a provisional application or national patent application or regional or international (PCT) patent application.

\section{Qualified Invention Disclosure}

An invention disclosure becomes a Qualified Invention Disclosure when it has been evaluated by the TTO/ILO staff or other technology experts to assess the commercial application and then accepted into the TTO/ILO system for further progression.

\section{Reference year}

The twelve-month reporting period from January 1st to December 31st.

\section{Research grant}

An award to an RPO by a research funding agency (e.g. government agency, charity) to perform a programme of research with the intention of disseminating the research results. Typical research funders may include: SFI, ERC, Wellcome Trust.

\section{RPO}

Research Performing Organisations. Universities and other research institutions funded primarily by public funds. Also referred to as PRO (Public Research Organisations)

\section{SME}

Has up to 249 employees and has either an annual turnover not exceeding $€ 50$ million or an annual balance sheet total not exceeding $€ 43$ million.

\section{SME Irish}

$\mathrm{HQ}$ based in Ireland.
Sole qualified invention/ software disclosure

Descriptions of tangible inventions/ software created within only one RPO that are evaluated by the TTO staff or other technology experts to assess their commercial application and then accepted into the TTO system for further progression.

\section{Spin-in}

Company formed external to the RPO, which is not based on RPO $I P$, research or resources, and which does not involve RPO staff or students. In becoming a spin-in the company becomes based in the RPO (e.g. within an incubator) and/or provides equity to the RPO in exchange for access to business services from the TTO.

\section{Spin-out}

A spin-out company is a new, incorporated business based primarily on knowledge and/or intellectual property originating from the RPO in which the RPO holds equity and/or has a licence to the IP.

\section{Start-up}

Company formed by staff or students from the RPO not based on knowledge or IP generated by the RPO and where there is no formal IP licence or equity share with the RPO. (Exclude spin-out or spin-in companies).

\section{TTO}

Technology Transfer Office - the team responsible for managing KT services, including intellectua property management, licensing, partnering with industry and the creation of new companies. 


\section{Notes}



KTI Knowledge Transfer Ireland

Enterprise Ireland

The Plaza

East Point Business Park

Dublin 3

T +353(0)1 7272000

E kti@knowledgetransferireland.com

w knowledgetransferireland.com 